\title{
Reducing Sulfur Emissions: Logistical and Environmental Considerations
}

\section{Zis, Thalis P. V.; Psaraftis, Harilaos N.}

\section{Published in:}

Sustainable Shipping

Link to article, DOI:

10.1007/978-3-030-04330-8_7

Publication date:

2019

Document Version

Peer reviewed version

Link back to DTU Orbit

Citation (APA):

Zis, T. P. V., \& Psaraftis, H. N. (2019). Reducing Sulfur Emissions: Logistical and Environmental Considerations. In H. N. Psaraftis (Ed.), Sustainable Shipping: A Cross-Disciplinary View (pp. 249-284). Springer. https://doi.org/10.1007/978-3-030-04330-8_7

\section{General rights}

Copyright and moral rights for the publications made accessible in the public portal are retained by the authors and/or other copyright owners and it is a condition of accessing publications that users recognise and abide by the legal requirements associated with these rights.

- Users may download and print one copy of any publication from the public portal for the purpose of private study or research.

- You may not further distribute the material or use it for any profit-making activity or commercial gain

- You may freely distribute the URL identifying the publication in the public portal

If you believe that this document breaches copyright please contact us providing details, and we will remove access to the work immediately and investigate your claim. 


\section{CHAPTER 7 \\ Reducing Sulphur Emissions: Logistical and Environmental Considerations}

Thalis Zis

Technical University of Denmark

tzis@dtu.dk

Harilaos N. Psaraftis

Technical University of Denmark

hnpsar@dtu.dk

\section{ABSTRACT}

In recent years the issue of sulphur emissions from maritime transport has seen newfound attention. This chapter presents an overview of the main issues of sulphur emissions and the legislative framework that seeks to reduce the sulphur footprint of the maritime sector. It also analyses potential modal shifts towards less efficient landbased modes which may happen as a result of sulphur regulations, and investigates the related potential economic damage to ship operators. To that effect, this chapter presents findings from a recently finished project at DTU, and the developed methodological framework that can be used to estimate such modal shifts, as well as to measure the efficacy of policy and ship operators' measures to reverse such shifts.

\section{LIST OF ACRONYMS AND ABBREVIATIONS}

BAF Bunker Adjustment Factor

CBA Cost Benefit Analysis

$\mathrm{CO}_{2}$ Carbon dioxide

CO Carbon monoxide

EC European Commission

EEDI Energy Efficiency Design Index

ETS Emission Trading System

EU European Union

GHG Greenhouse Gas

IMO International Maritime Organization

HFO Heavy Fuel Oil

LNG Liquefied Natural Gas

MDO Marine Diesel Oil

MGO Marine Gas Oil

$\mathrm{NO} \times$ nitrogen oxides

Ro-Ro Roll-on Roll-off

Ro-Pax Ro-Ro with Passengers

SECA Sulphur Emission Control Area

$\mathrm{SO}_{x}$ sulphur oxides

SSS Short-Sea Shipping

WHO World Health Organization 


\section{INTRODUCTION}

The purpose of this chapter is twofold: (a) present the main general issues associated with the reduction of sulphur emissions in maritime transport, and (b) focus on a specific study which has investigated possible modal shifts as a result of sulphur regulations, as well as possible actions to mitigate and reverse such modal shifts.

\subsection{Background: What are $\mathrm{SO}_{\mathrm{x}}$}

In order to understand the recent attention of the shipping community on the issue of sulphur emissions, it is important to first present this pollutant species in brief. Sulphur oxides $\left(\mathrm{SO}_{\mathrm{x}}\right)$ refers to the family of chemical compounds formed from atoms of sulphur and oxygen. $\mathrm{SO}_{x}$ may refer to one of the following: $\mathrm{SO}$ (sulphur monoxide), $\mathrm{SO}_{2}$ (sulphur dioxide), $\mathrm{SO}_{3}$ (sulphur trioxide), $\mathrm{S}_{2} \mathrm{O}$ (disulphur monoxide), $\mathrm{S}_{2} \mathrm{O}_{2}$ (disulphur dioxide), lower sulphur oxides $\left(\mathrm{SnO}_{\mathrm{n}}, \mathrm{S}_{7} \mathrm{O}_{2} \mathrm{~S}_{6} \mathrm{O}_{2}\right)$. Most of these $\mathrm{SO}_{x}$ are unstable and rarely encountered in nature. However, $\mathrm{SO}_{x}$ produced by fuel combustion in marine engines predominantly contain $\mathrm{SO}_{2}$ emissions which is the main subject of this section. Sulphur dioxide is a chemical compound that consists of two oxygen atoms and a sulphur atom. Its molar mass is equal to $64.066 \mathrm{~g}$ per mol. $\mathrm{SO}_{2}$ is in gaseous form at standard temperature and pressure and exists in Earth's atmosphere in very small concentrations of approximately 1 ppbv (Pickering and Owen, 1997). Chemically, $\mathrm{SO}_{2}$ is produced following the oxidation of sulphur or other materials that contain sulphur according to the following chemical reaction:

$\mathrm{S}+\mathrm{O}_{2} \rightarrow \mathrm{SO}_{2}$

Fossil fuels (coal and oil) contain varying amounts of sulphur according to their purpose which typically varies between 0.10 and $5 \%$.

$\mathrm{SO}_{2}$ has a dual nature as a global and local pollutant. It is considered a hazardous pollutant that can cause nerve stimulation in the lining of the nose and throat and affects people with asthma. Further oxidation of $\mathrm{SO}_{2}$ occurring in the presence of $\mathrm{NO} 2$ (which is also generated during fuel combustion) forms sulphuric acid $\left(\mathrm{H}_{2} \mathrm{SO}_{4}\right)$. This contributes substantially to form acid rain which in turn interferes with the growth of flora and fauna and also affects water-life (Cullinane and Cullinane, 2013).

Sulphur dioxide is generally not considered a greenhouse gas (GHG). In fact, it has been argued that $\mathrm{SO}_{2}$ only has a cooling effect. In the pre-industrial era climate change is credited to have started by major changes in volcanic activity which release large quantities of $\mathrm{SO}_{2}$ (Crowley, 2000). Major historic volcanic eruptions have led to the cooling of the earth's surface; however Ward (2009) concludes that this happens only when such volcanic eruptions are sporadic and large. Large eruptions in quick succession (e.g. at least one each year for a period of ten or more years) would impair the oxidizing capacity of the atmosphere, leading to the accumulation of GHGs. Ward 
therefore shows that $\mathrm{SO}_{2}$ can indirectly contribute to global warming. The combustion of fossil fuels every 1.7 years is emitting as much $\mathrm{SO}_{2}$ as one large volcanic eruption (as measured in Greenland). The largest source of $\mathrm{SO}_{2}$ emissions is fossil fuel combustion at power plants (approximately $73 \%$ ) and other industrial facilities (20\%), while smaller sources include the burning of high sulphur containing fuels by locomotives, non-road equipment and large ships (EPA, 2013). The World Health Organization (WHO) recommends that a concentration of $500 \mu \mathrm{g} / \mathrm{m}^{3}$ should not be exceeded over averaging periods of 10 minutes duration and that the 24-hour mean should be less than $20 \mu \mathrm{g} / \mathrm{m}^{3}$. The ten minute period is justified as such short periods of exposure of asthmatics to $\mathrm{SO}_{2}$ may provoke changes in pulmonary function and respiratory symptoms. Longer term exposures to $\mathrm{SO}_{2}$ together with other pollutants contribute to changes in mortality, morbidity or lung function (WHO, 2005). In the European Union, legislation suggests that the 1-hour mean should not exceed $350 \mu \mathrm{g} / \mathrm{m}^{3}$ whereas the 24-hour mean should be less than $125 \mu \mathrm{g} / \mathrm{m}^{3}$. The maximum allowed number of exceedances each year is 24 and 3 respectively (European Commission, 2008) which is less strict than the WHO guidelines. Comparing the two standards, the EU limit is more tolerant on its daily mean value which can be interpreted as a consequence of the better air quality in comparison to countries that rely more on coal and fossil fuels for their energy production.

\subsection{Relevant Regulation}

In response to these limits, the IMO and the EU have set specific limits on the sulphur content of fuel used near and at ports.

In 1997, the Kyoto Protocol of the UN framework convention on climate change requested that the IMO considered and addressed the issue of ship emissions. In response, the IMO commissioned a study on GHG emissions with a focus of identifying feasible reduction strategies. In 1977 limits for the main air pollutants from exhaust gas from ships were introduced through the MARPOL Annex VI. The second GHG study was commissioned and estimated the global contribution of shipping in $\mathrm{CO}_{2}$ emissions at 2.7\% (Buhaug et al., 2008). The revised MARPOL Annex VI introduced limits on the maximum sulphur content allowed in bunker oil and created designated sulphur emission control areas (ECAs) where tighter limits applied. The first ECA for $\mathrm{SO}_{\mathrm{x}}$ emissions was the Baltic Sea which was designated in 1997. However, it was not until 2005 that the ECAs were enforced. The next ECA was the North Sea which was adopted in 2005 and enforced in 2006. In 2010 the North American ECA was designed, and enforced in 2011. In 2011 the United States Caribbean Sea ECA was adopted and enforced at the beginning of 2013. Activity in the ECAs would be in effect one year after the area was enforced. Figure 1 presents the progression of the maximum sulphur content in bunker oil within and outside SECAs. 


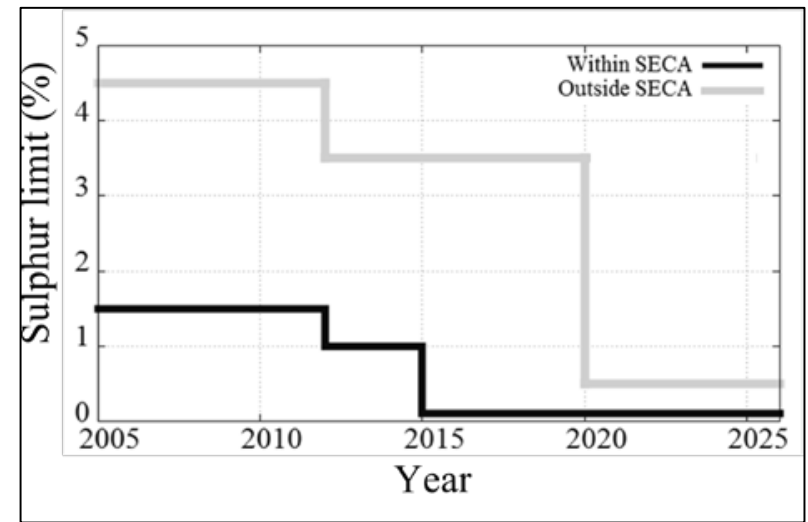

Figure 1: Maximum allowed sulphur fuel content (\%)

The regulation dictates that from 2020 onwards, the global limit of sulphur content will be $0.50 \%$ (outside SECAs), a decision that was confirmed at the 70th session of IMO's Marine Environment Protection Committee (MEPC 70) in October 2016 after a long debate on low sulphur fuel availability. The further designation of SECAs has been suggested by Cullinane and Bergqvist (2014) due to the social benefits due to the regulation. Regarding $\mathrm{NO}_{x}$ emissions, marine diesel engines on-board ships must meet certain performance standards defined by MARPOL VI. This will also provide a positive impact on the near-port air quality. The US ECAs are also NECAs (Nitrogen Emission Control Areas), whereas for the European ECAs (North and Baltic Sea) the NOx limits will be enforced from 2021. The specifications for $\mathrm{NO}_{x}$ emissions are presented in Figure 2 for the different tiers of the regulation (based on the ship construction date) and the resulting emission limits are plotted.

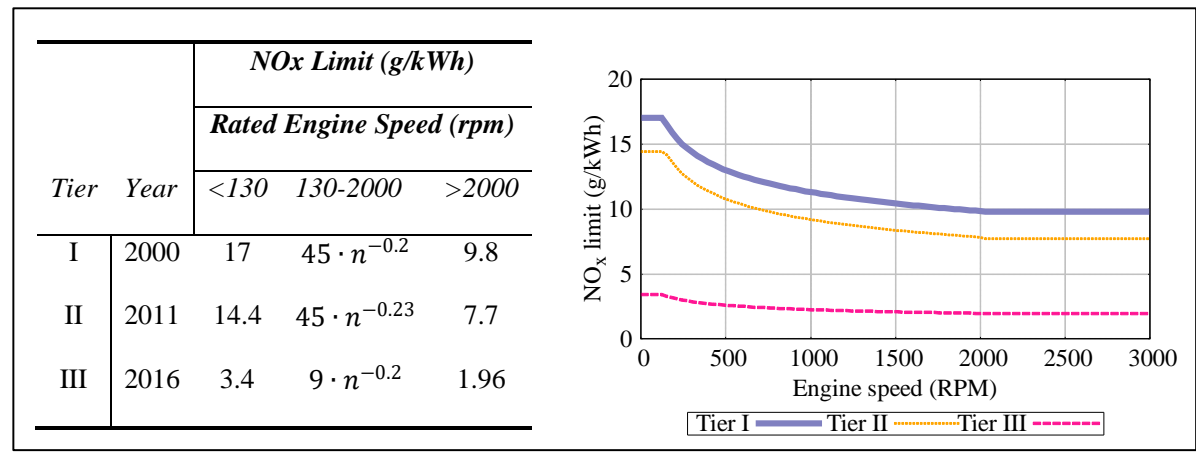

Figure 2: NOx emission limits (MARPOL Annex VI). Source: Zis (2015)

Tier II describes the current $\mathrm{NO}_{\mathrm{x}}$ limits for engines anywhere in the world, whereas Tier III will apply for ships built on or after the $1^{\text {st }}$ of January 2016 and sailing in $\mathrm{NO}_{x}$ ECAs. For these vessels sailing outside ECAs the Tier II limits will apply. As the limits in sulphur content will soon reach very low values there, it is envisioned that existing zones will be expanded and new areas introduced. 
The introduction of SECAs and their progressively stricter limits have shown to be a considerable success on limiting $\mathrm{SO}_{\mathrm{x}}$ emissions of the sector. The most cited figure on the contribution of international shipping on $\mathrm{SO}_{x}$ emissions is the one provided by Eyring et al (2005) which ranges between 5 and $8 \%$, but that was at a time where no sulphur limits were in place. Zis and Psaraftis (2018) provide a more recent estimate on sulphur emissions that is extracted from data of the Organisation for Cooperation and Development (OECD). For 2015, OECD estimates that transportation (mobile sources) accounted for $3.45 \%$ of the total sulphur oxides emissions within the OECD countries, $14 \%$ of which was attributed to road transport (OECD, 2017). This shows that the recent regulation on limiting $\mathrm{SO}_{\mathrm{x}}$ emissions from the maritime sector has seen considerable success, and it can be expected that post-2020 the global contribution will be even lower when the global sulphur cap is enforced.

\subsection{Compliance with the regulation}

To comply with the regulation within SECAs, ship operators can either use ultra-low sulphur fuel (such as MGO or MDO) or rely in abatement technologies that result in the same $\mathrm{SO}_{x}$ emissions reduction (for example, use of scrubber systems).

Low sulphur MGO is pure distillate oil that contains less than $0.10 \%$ sulphur and can be used in conventional marine engines within ECAs and other sulphur regulated areas (e.g. EU ports). This fuel can be used without major modifications, but one drawback is that it has to be stored at a different tank for vessels that use fuel switching. MGO in general has a lower viscosity than HFO, and as a result additional lubrication must be used to avoid damage in the engine's pumps (MAN, 2014). Historically, fuel with lower sulphur content is more expensive than regular bunker oil. Low-sulphur fuel requires additional refining which can also result in additional transportation (from production facility to refinery) with environmental (e.g. increased carbon footprint) and economic implications. The price differential among different fuel types is not constant and as all fuel prices it is also characterized by significant volatility.

Scrubber systems are neutralizing sulphur oxides by filtering the exhaust gases through water which results in sulphate containing waste water that is recirculated into the sea. Three main types of scrubber systems are currantly used depending on the water use to wash out the sulphur oxides. These are:

- Seawater systems (open-loop)

- Freshwater systems (closed-loop)

- Hybrid systems

The first type can use seawater for the scrubbing process so long as the alkalinity of the water is sufficient (Henriksson, 2007). In other cases (notable examples are the waters in the Baltic Sea and near Alaska) it is necessary to use freshwater systems. Finally, hybrid systems allow the change of water depending on where the vessel is operating. All types of scrubber systems can be installed on both new builds and older vessels (retrofitted). The latter is more costly, and there are additional considerations on the space capacity available to install the system and where necessary the freshwater tanks (DMA, 2012). In terms of environmental performance, freshwater scrubber systems are reported to reduce Sox by up to $97 \%$ and PM emissions by an 
estimated 30 to $60 \%$ when HFO of up to $2.5 \%$ sulphur is used (EMSA, 2010). However, these emissions reductions do not take into account the increase in the overall fuel consumption that is associated with the scrubber systems' energy requirements.

The total capital cost required to install a scrubber system depends on the type (open or closed loop) and size of the installation. Rough estimates include a cost range of between 100 and 200 Euros per kW of installed power on new builds, and 200-400 Euros for retrofitting installations. More detailed information from EMSA is given in Table 1 below.

Table 1: Capital costs for scrubber systems. Source: EMSA (2010)

\begin{tabular}{l|lll} 
Scrubber system & Vessel & Cruise ferry ( 40MW) & Cargo ship ( 20 MW) \\
\hline \multirow{2}{*}{ Seawater system } & New build & $3 \mathrm{M} €$ & $2.1 \mathrm{M} €$ \\
& Retrofit & $3.5 \mathrm{M} €$ & $2.4 \mathrm{M} €$ \\
\multirow{3}{*}{ Freshwater system } & New build & $2.4 \mathrm{M} €$ & $1.9 \mathrm{M} €$ \\
& Retrofit & $3.4 \mathrm{M} €$ & $2.4 \mathrm{M} €$ \\
Hybrid system & New build & $3.8 \mathrm{M} €$ & $2.6 \mathrm{M} €$ \\
& Retrofit & $4.3 \mathrm{M} €$ & $3 \mathrm{M} €$
\end{tabular}

Additionally, there are operating and maintenance costs associated with the use of scrubbers. A very important extra cost stems from the increased fuel consumption to cover the energy requirements of the scrubbers. This varies per technology type, and is estimated at approximately $1-3 \%$ for seawater systems, and $0.5-1.5 \%$ for freshwater scrubbers. Therefore, no matter which compliance option the affected ship operators choose, their operating costs will increase.

\subsection{Impacts of sulphur regulations on short sea shipping}

As low-sulphur fuel (Marine Gas Oil-MGO or Marine Diesel Oil-MDO) is substantially more expensive than Heavy Fuel Oil (HFO), there is little or no room for the Short-Sea Shipping Sector to absorb such additional costs and thus significant price increases must be expected on their freight rates. Unlike its deep-sea counterpart, in short-sea shipping such a freight rate increase may induce shippers to use land-based alternatives (mainly road). A reverse shift of cargo would go against the EU policy to shift traffic from land to sea to reduce congestion, and might ultimately (under certain circumstances) increase the overall level of $\mathrm{CO} 2$ emissions. If the shipping price is no longer competitive with road transport, this will likely have one or more of the following ramifications:

- Modal Shifts towards land-based options and possible congestion

- Loss of cargo volumes for shipping companies

- Reduced profits or increased losses

- Potentially more $\mathrm{CO}_{2}$ in the overall supply chain 
- Increased cost of the produced goods, making these products uncompetitive as compared with sourcing from other areas, including areas outside the EU and thus among others, additional transport-related emissions

- The loss of business may hinder the shipping routes non-viable and thus candidates for closure. A consequence is that all of the remaining cargoes on such routes will need to find alternative transport routes, most likely road.

This chapter will present the issues that $\mathrm{SO}_{x}$ emissions may create on the shipping sector, with a particular focus on the short sea shipping (SSS) sector and more specifically an application on Ro-Ro services in the North and Baltic Sea.

These increased operating costs will partially be passed on to shippers via increased freight rates. This could have more severe consequences for short sea shipping (SSS) operators as these compete heavily with other transportation modes (such as rail and road). As a result, modal shifts could be triggered due to the regulation.

\subsubsection{Anticipated impacts before the new limit}

In fact, there were numerous media reports during 2013 and 2014 (before the $0.10 \%$ limit) that hinted on potential closures of SSS services in the affected areas, as well as possible new rail links to absorb an increased transportation demand arising from previous closures.

Some ship operators started investing in scrubber systems years ahead of the new limit, in response to the new regulation. To assist the early adapters, the European Commission provided subsidies for capital investment costs, reaching up to $20 \%$ of the total system installation costs ${ }^{1}$.

A cost-benefit analysis (CBA) study by Jiang et al. (2014) compared investment in scrubber systems vs the use of low-sulphur fuel to comply with the regulation. They concluded that scrubber systems are more beneficial when installed in new builds than retrofits, but also noted that only if the lifespan of the vessel is more than four years scrubbers are worth consideration. These conclusions agree with the overall view in the industry that scrubber systems were the way forward ahead of the new limits. However, these conclusions were drawn based on the high fuel prices at the time, and the important price differential between the different fuels. In a more recent study, Zis et al. (2016) argued that with the unexpectedly low fuel prices for both MGO and HFO during 2014-15, the payback period of an investment in scrubber systems (retrofit) has in some cases more than doubled, reaching 10 years for small vessels operating most of their time within SECA. Therefore in retrospect, the low fuel prices support the argument that investments in scrubber systems were not the best option. This can be further supported by the fact that in 2020 the global cap of sulphur content will be lowered to $0.50 \%$ (certainly in European waters regardless of the outcome of the IMO review on postponing the limit to 2025), and thus the fuel price differential will be lower once the limit kicks in.

In 2010 the Institute of Shipping Economics and Logistics (Lemper et al., 2009)

\footnotetext{
${ }^{1}$ Source: $\underline{\text { http://www.cosbc.ca/index.php/international/item/1748-eu-hands-out-scrubber-subsidies }}$
} 
estimated that modal shifts due to the new limit after 2015 could reach on average $22 \%$ (considering container and Ro-Ro shipping). The study anticipated an increase in sea transport costs for all fuel scenarios (high and low prices), however even the low fuel price scenarios were actually much higher than the actual fuel prices. In 2013, a study from the North Sea Consultation Group (Odgaard et al., 2013) examined the potential modal shifts following the establishment of NECA and SECA in the North Sea and the Baltic. The study reports an anticipated increase in sea transportation costs ranging between 8 and $16 \%$, reduced to $5-13 \%$ when the road haulage is included.

\subsubsection{What actually happened after the new limit}

The previous section tried to capture the gloom and doom that was the prevailing mood of the industry at the time before the new limit. Certain operators had already shut down routes (Stena line, DFDS) or significantly altered their service schedules (different sailing speeds, lower frequencies, new fleet assignment). There were also fears that manufacturing, mining, and forest industries in the area could relocate due to the increased transportation costs. Despite the concerns, most SSS operators saw a very positive year in 2015. In fact, some of the larger Ro-Ro operators reported record revenues over the year. This unexpected turn of events cannot be attributed to the lower sulphur limit, but rather to the significant and entirely unexpected drop in fuel prices since the mid of 2014. This is shown in Figure 3 that presents the fuel price fluctuation in the period of 2014 to 2017 , for MGO in the green line $(0.10 \%$ sulphur content), HFO in the salmon line ( $1 \%$ sulphur content) and their price differential in the black trendline.

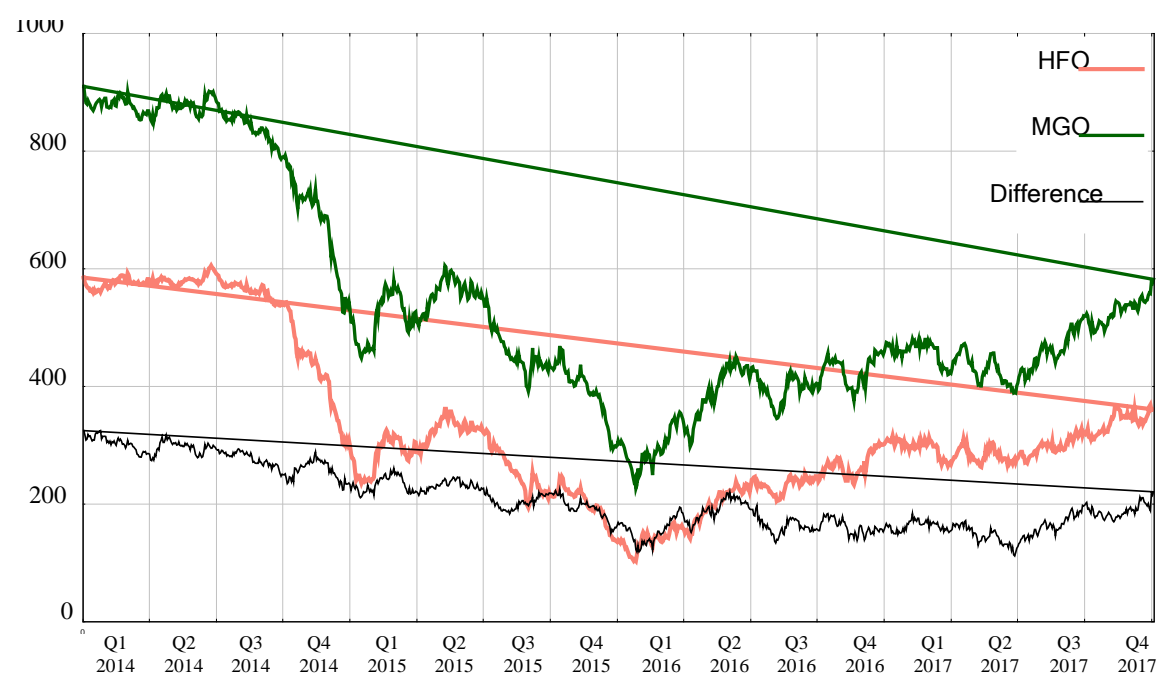

Figure 3: Fuel prices 2014-2017. Data source: www.bunkerworld.com

The price differential between the two types of fuel, can be seen to gradually decline in absolute terms during the first year of the new limit. One can observe that in 2015 
the MGO price was lower than the HFO price in 2014. This means that despite the stricter regulation, the fuel cost was actually lower for ship operators compared to the year before the limit. This would in turn allow ship operators to offer similar (and in some cases lower) freight rates as in 2014 , but operate on lower overall costs. This fact may explain the record revenues recorded in 2015. It has to be noted though that fuel prices have started increasing again since 2016, a trend which if continued could have major implications on modal shifts to land based options if they continue to do so and reach previous higher levels. The repercussions of the global sulphur cap on fuel prices are also an important question for the near future.

\subsection{Structure of the rest of this chapter}

The previous sections presented in very brief the main challenges that SOx emissions have put on the maritime sector, and particularly the SSS sector that was immediately affected by it. The next sections of this chapter present work undertaken in the context of the RoRoSECA project at DTU during the period 2015-2017, and a methodology that can be useful in answering the following questions:

- What are the economic impacts of sulphur legislation?

- What are the environmental impacts and what trade-offs emerge?

- How can modal shifts be modelled?

- What measures can ship operators take to mitigate and reverse the situation?

- What policy measures can assist in ensuring that the sulphur legislation is not hurting the SSS?

- How can the proposed methodology be applied in other shipping sectors to examine the impacts of the global sulphur cap?

\section{Modeling modal shifts}

This section presents an enhanced modal split model that was developed to estimate modal shifts caused by the introduction of the new sulphur limit. The model was subsequently applied in a set of Ro/Ro routes within the North and Baltic Sea. Section 2 of this chapter is an adaptation of the work of Zis and Psaraftis (2017).

\subsection{Logit models}

Modal split models are useful to facilitate the simulation of travel demand between an O-D pair amongst a set of different transport modes. The underlying theory is based on the assumption that the decision maker (in this case the shipper) seeks to maximize his utility (or minimize his disutility) by selecting the optimal transport mode. In the context of this chapter the shipper aims to minimize their perceived generalized cost of transport.

In theory, this would lead to an all or nothing assignment, as a simple enumeration of the total generalized costs could show which option has the minimum. However, in reality each decision maker will have a different perception of what the lower cost is. In transportation, the majority of modal split models used are falling in the category of logit models, as these are found to fit mode choice behavior quite well (Panagakos et al., 2014). Logit models are special cases of regression models where the dependent variable is discrete. The purpose of logit models is to predict the probability of particular outcomes (mode choice) based on one or more explanatory variables. 
Logit models can have a binary structure (where there are only two options available), an $\mathrm{N}$-way structure (three or more options uncorrelated to each other), or a hierarchical (nested) structure where the decision maker selects first a group of options that are related to each other, and subsequently selects one of the options within that group (nest). These three forms are shown schematically in Figure 4.

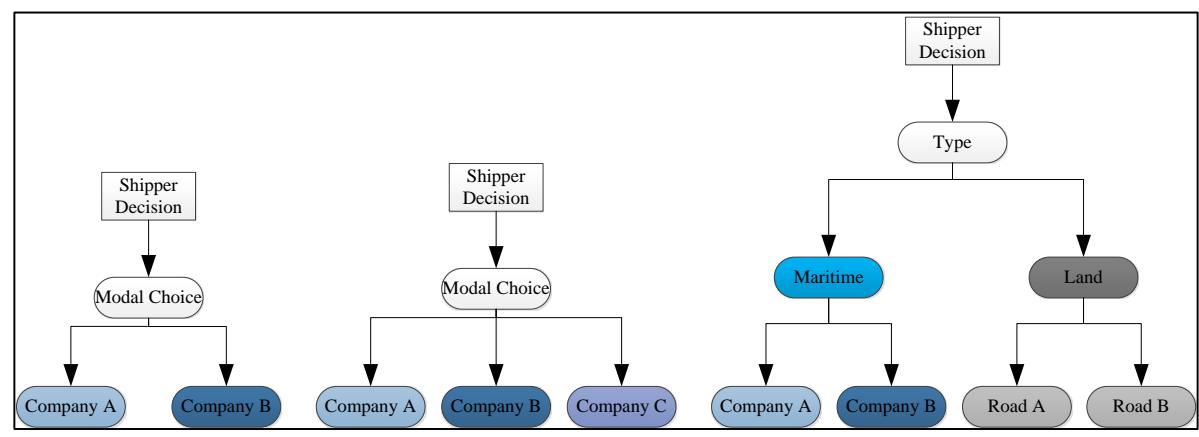

Figure 4: The different types of nested models (binary, N-way, nested)

In this work, the assumption is that a shipper follows a hierarchical decision making process, where they need to first select whether to make use of a maritime mode or not, and subsequently decide which transport suppler (which maritime company) to use, or which route if using a land-based mode. The assumption is that the maritime modes are correlated to each other, and the land-based modes respectively. Let GCi expressed in $€$ per lanemeter $(€ / / \mathrm{lm})$ be the generalised cost of transport via mode $\mathrm{i}$. In this case, a first split between the maritime $(M)$ and land $(L)$ modes is assumed. The probability $p_{n}$ of choosing a maritime mode $M$ is given by equation 1 .

$p_{M}=\frac{e^{-\lambda_{1}^{i} \cdot G C_{M}}}{\sum_{n=M, L} e^{-\lambda_{1}^{i} \cdot G C_{N}}}$

Where $\lambda_{1}^{i}$ is the dispersion parameter between the two nests. $G C_{N}$ represents the composite generalized cost for nest $\mathrm{N}$, and is a function of the generalized cost of all $j$ alternatives in nest $\mathrm{N}$.

Assuming that the first decision revolves around which type of mode is selected ( $M$ or $L$ ), and that the decision is a maritime mode $j \in M$, the shipper must now decide which of the available $j$ maritime options to use. The hierarchical structure is then assuming that the conditional probability $P_{j / N}$ of choosing mode $\mathrm{j}$ when nest $N$ is selected:

$P_{j / M}=\frac{e^{-\lambda_{M} \cdot G C_{j / M}}}{\sum_{j \in M} e^{-\lambda_{M} \cdot G C_{j / M}}}$

And (if there are only two options in $M$ )

$P_{1 / M}+P_{2 / M}=1$

Where $\lambda_{M}$ is a dispersion parameter for the secondary split amongst the maritime modes. A similar $\lambda_{L}$ dispersion parameter for the secondary split among the landbased modes is also defined. Equation 7 shows that if there are only two alternatives 
in the maritime nest, then all commodities selecting a maritime mode will be transported via maritime option 1 or 2 . At this level, it is possible to have more options of a similar type (e.g. a third maritime option) which is assumed to follow an N-way structure (within the maritime nest) and thus share the same secondary dispersion parameter $\lambda_{M}$.

These secondary dispersion parameters can be calibrated as in the binary or $\mathrm{N}$-way structure if the generalized cost of each option within the nest, and its associated market share are known. Having estimated the secondary dispersion parameters, it is possible to estimate the so called composite generalized cost $G C_{N}$ seen in equation 5 . This composite cost $G C_{N}$ for nest $N$ is calculated through equation 4.

$G C_{N}=\frac{-1}{\lambda_{N}} \log \left(\sum_{\mathrm{j} \in \mathrm{N}} e^{-\lambda_{N} \cdot G C_{j / N}}\right)$

According to eq. 8 , if there is only one alternative $\mathrm{j}$ between a similar mode of type $\mathrm{i}$, then the composite cost collapses into the generalized cost $G C_{j}$ of that mode. In a similar manner, if there are only two modes of type i (for example $L$ and $M$ for landbased and maritime), and for each type there is only one alternative, then the hierarchical model collapses into a binary logit model of only two options. Therefore, the described structure can be readily applied to all types of case studies affected by the SECA regulation. These can be:

- Routes that face no competition from land-based modes, but more than one shipping operators are serving

- Routes with a unique shipping operator and one land-based alternative

- A combination of the previous

It has to be noted that there could be a hierarchical structure with more than 2 nests (for example a maritime, a road, and a rail nest) but this is not considered in this chapter.

\subsection{Modeling framework}

A six-step modeling framework is created to identify the impacts of the regulation on SSS. The first step in this process is concerned with the data collection on the situation of the market before any changes (in this case the introduction of the new limit). After gathering the necessary data, it is possible to decide which for of logit model will be used for the examined shippers' options. The model is then calibrated in the second step, and the scale parameters are estimated. In the third step, the new generalized costs following the new limits are estimated for each travel option. For example, if the fuel price increases and no other change is introduced, it is possible to estimate the new freight rate for any maritime legs based on information on the bunker adjustment factor. Using the calibrated model, and having calculated the new generalized cost for each option it is now possible to retrieve the new market share of each option. In the fourth step, the new environmental balance of the system (emissions from all modes in each option) and the new route profitability of each maritime link is estimated. If one of the two is not satisfactory step 5 and step 6 are respectively examining whether an operators measure or a new policy can mitigate or reverse the unsatisfactory situation of step 4. The whole process is depicted in Figure 5 below. The next sections of this chapter will present the effects of the operators and policy measures on a set of representative case studies. 


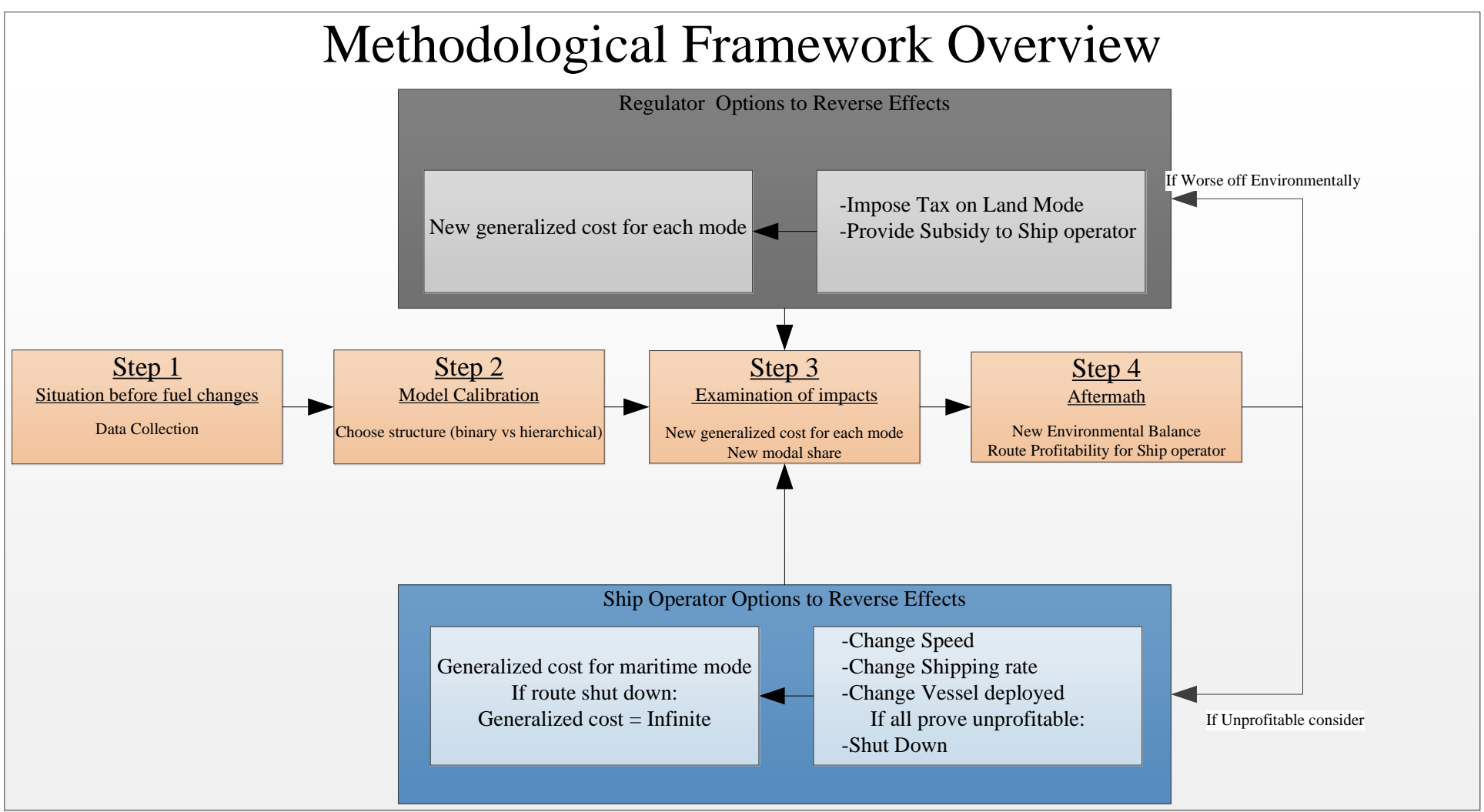

Figure 5: The modelling framework to examine impacts of the new sulphur limits on SSS 


\subsection{Data collection and assumptions}

For the model calibration of any modal split model there are some necessary data that need to be collected. Most discrete choice models use the so-called revealed preference data to predict aggregate market behavior (Ben-Akiva et al., 1994), and require information on the key explanatory parameters (for example travel times, travel costs, number of interchanges, time of travel, weather condition, etc.,). An alternative approach is the use of stated preference data, which revolve around observations on hypothetical choice behavior, typically collected through surveys, interviews or focus groups. Necessary data require the acquisition of information on the market share of each of the available options (e.g. how many users select each available option) to model the probability of making a selection. Subsequently, one has to decide which of all the explanatory variables should be used in the model during the calibration stage.

Most of the aforementioned discrete choice models used in transportation are focusing on the behavior of passengers or drivers, and differentiate between the various transportation modes that are available to them. Ortúzar and Willumsen (2011) classify the factors influencing mode choice that include among others travel cost, travel time, number of transit changes, weather, comfort, vehicle availability, trip purpose, income, time of day. In contrast, for freight transport the shipper usually has to decide based on fewer influencing factors, mainly the total travel cost and overall time, taking into consideration the reliability of service. Nam (1997) considers as explanatory variables for freight transport the shipment weight, freight charge, commodity type, distance, travel time, and frequency of service. These can all be transformed into cost and time for each option. In this work, the focus is on modelling the mode choice of shippers when one or more short-sea shipping modes are available and compete with each other and with one or more land-based model. A key assumption here is that the shipper decides solely on information about total travel cost and time, as these are the explanatory variables that are heavily affected by changes in policies and the examined operators' measures.

The necessary steps for the data collection before calibrating the model are the following:

- $\quad$ Enumerate all competing modes (maritime and/or land-based)

- $\quad$ Select origin - destination (O-D) pairs for shipments that may use the Ro-Ro service

- Estimate of the total travel time for each available option in the transportation system

- Collect information on freight rates to estimate total transportation cost for each option

- $\quad$ Gather information on transported volumes for each option as (\%) market shares

In an ideal scenario, all O-D pairs for all cargoes travelling through the available options will be collected. That info should contain the value and weight of cargo for each shipment, its depreciation rate which may vary significantly from product to product, the total travel time (including waiting times during mode changes), the travel cost as experienced by the shipper (which may vary if the shipper is a longtime 
customer or sends very big shipments), as well as any information on delayed or incomplete journeys. However, this sort of data are realistically impossible to obtain. Ro-Ro ship operators typically set their freight rates in $€$ per lanemeter (Im), which measures the volume of that the cargo takes onboard the vessel. Information on the actual weight of the transported trailers are not controlled by the Ro-Ro operator and only an estimation can be made based on the cargo type (if that is known). However for land-based options, the weight of the cargo is more important as it also has a more significant impact on the fuel consumption of the road vehicle. Typically freight rates are confidential and negotiated on an individual customer level (with provision of bulk discounts etc.). In this work, we use the average freight rate ( $€$ per lane meter) that the shipping company was charging for each of the examined routes. Therefore, one weakness in our model is that during calibration, a drastic discount to a large supplier that may have prompted them to decide an all or nothing assignment between the available options is not considered. In the real world, apart from cost and travel time a shipper may have a strong preference on a mode or service provider that cannot be explicitly modelled without direct information from the shipper. These shippers would therefore be inelastic and more reluctant to switch modes despite a small increase in the cost of one of the options. Due to the aforementioned limitations, this chapter presents a calibrated model that considered an aggregate case for the examined shipping network. However, the modelling framework could easily handle more disaggregate data should these become available in the future.

\subsection{Selection criteria of routes and model calibration}

This section presents the calibration results of seven routes in the North and Baltic Sea of a leading Ro-Ro operator. The selection of the seven routes was based on balancing the following criteria:

- Sailing distance

- Sailing frequency

- Deployed capacity

- Abatement technology (scrubbers vs low-sulphur fuel)

- Cargo types

- Vessel type (Ro-Ro, Ro-Pax, Pax)

The routes comprise of a mixture of cargo-only services (Ro-Ro), services that also carry passengers (Ro-Pax), and predominantly passenger services with limited cargo capacity (Pax). The Ro-Ro operator provided information on transported volumes (lanes per trip), freight rates $(€ / \mathrm{lm})$, passengers on-board (for Ro-Pax services), passenger fares (€/pax), on-board spending $(€ / \mathrm{lm})$, fleet deployment, and fuel consumption for each vessel on each service for 2014 and 2015. The seven routes are a representative subset of the full Ro-Ro network that the operator is serving.

Based on these criteria, the examined services are the following:

- $\quad$ Gothenburg - Ghent (Ro-Ro - North Sea)

- $\quad$ Esbjerg - Immingham (Ro-Ro - North Sea)

- $\quad$ Rotterdam - Felixstowe (Ro-Ro - North Sea)

- $\quad$ Copenhagen - Oslo (Pax - North Sea) 


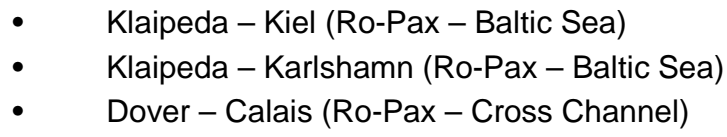

The modelled unit of transport in the problem is the lanemeter of cargo for all competing modes in the analysis. It should be noted that information on the origin and final destination of the cargoes using the maritime links were not known to the collaborating ship operator for all cargoes. In addition, disaggregate level information on freight transport flows for the full European road network were also not possible to retrieve. To deal with these limitations, the calibration of the logit model was performed using a simulation approach where sensitivity analyses around central values for key characteristics (market shares, road distances, freight rates for land-based options) were conducted. The characteristics along with an aggregate data summary for 2014 and 2015 is shown in Table 2, showing only percentage changes between the two years (and not exact values) due to a confidentiality agreement with the shipping company that provided the datasets. These were the data for step 1 of Figure 5. 
Table 2. Overview of examined services and changes between 2014 and 2015. Source: own compilation from data provided by operator. See also Zis and Psaraftis (2018)

\begin{tabular}{|c|c|c|c|c|c|c|c|c|c|c|}
\hline Route & $\begin{array}{l}\text { Distance } \\
\text { (NM) }\end{array}$ & $\begin{array}{l}\text { Sailing Speed } \\
\text { (knots) }\end{array}$ & $\begin{array}{c}\text { Frequency } \\
\text { (sailings/week) }\end{array}$ & $\begin{array}{c}\text { Fleet and } \\
\text { Abatement }\end{array}$ & Year & $\begin{array}{l}\text { Trips } \\
\text { Total }\end{array}$ & $\begin{array}{c}\Delta \text { Cargo } \\
\text { Volume (\%) }\end{array}$ & $\begin{array}{c}\Delta \text { Freight } \\
\text { Rate change } \\
(\%)\end{array}$ & $\begin{array}{c}\Delta \text { Revenue } \\
\text { (\%) }\end{array}$ & $\begin{array}{c}\Delta \text { Fuel Cost } \\
(\%)\end{array}$ \\
\hline $\begin{array}{l}\text { Gothenburg } \\
\text { Ghent }\end{array}$ & 577 & 18.1 & 6 & 3 Scrubber & $\begin{array}{l}2014 \\
2015\end{array}$ & $\begin{array}{l}553 \\
569\end{array}$ & 6.06 & -5.62 & 0.09 & -52.89 \\
\hline $\begin{array}{c}\text { Esbjerg } \\
\text { Immingham }\end{array}$ & 326 & 18.1 & 6 & $\begin{array}{l}1 \text { Scrubber } \\
1 \mathrm{MGO}\end{array}$ & $\begin{array}{l}2014 \\
2015\end{array}$ & $\begin{array}{l}512 \\
580\end{array}$ & 19.46 & -0.5 & 18.85 & -15.29 \\
\hline $\begin{array}{l}\text { Rotterdam } \\
\text { Felixstowe }\end{array}$ & 121 & 16.1 & 16 & $\begin{array}{l}2 \text { Scrubber } \\
1 \mathrm{MGO}\end{array}$ & $\begin{array}{l}2014 \\
2015\end{array}$ & $\begin{array}{l}1514 \\
1637\end{array}$ & 15.13 & 0.5 & 15.71 & -24.34 \\
\hline $\begin{array}{l}\text { Copenhagen } \\
\text { Oslo }\end{array}$ & 272 & 15.5 & 7 & $\begin{array}{l}1 \text { Scrubber } \\
1 \mathrm{MGO}\end{array}$ & $\begin{array}{l}2014 \\
2015\end{array}$ & $\begin{array}{l}687 \\
702\end{array}$ & -5.82 & 1.58 & 4.28 & -9.36 \\
\hline $\begin{array}{l}\text { Klaipeda } \\
\text { Kiel }\end{array}$ & 397 & 18.4 & 6 & 2 Scrubber & $\begin{array}{l}2014 \\
2015\end{array}$ & $\begin{array}{l}611 \\
615\end{array}$ & -4.64 & -7.71 & -8.89 & -30.05 \\
\hline $\begin{array}{l}\text { Klaipeda } \\
\text { Karlshamn }\end{array}$ & 223 & 17.2 & 7 & $\begin{array}{l}1 \text { Scrubber } \\
1 \mathrm{MGO}\end{array}$ & $\begin{array}{l}2014 \\
2015\end{array}$ & $\begin{array}{l}717 \\
710\end{array}$ & 3.64 & -2.32 & 3.73 & -22.99 \\
\hline $\begin{array}{l}\text { Dover } \\
\text { Calais }\end{array}$ & 26 & 15.3 & 99 & $2 \mathrm{MGO}$ & $\begin{array}{l}2014 \\
2015\end{array}$ & $\begin{array}{l}6210 \\
4994\end{array}$ & -17.66 & 9.36 & -18.04 & -50.35 \\
\hline
\end{tabular}


Using these data, and the modelling framework presented in Section 2.2, the modal split model was calibrated for each route. For the information on the market shares of other options ranges around central values based on aggregate statistical information form Eurostat and the Shippax CFI journal were used. The market share information was also discussed with relevant experts in roundtable meetings in the duration of the project. The calibration results are shown in Table 3 considering only cargo flows for all routes, and the whole range of market shares during the simulation is shown for each route. The resulting scale parameters are the averages of the simulation process. For more information on the model calibration, the readers are referred to the paper of Zis and Psaraftis (2017) that explains this process in further detail.

Table 3. Calibration results for the examined services. Source: Zis and Psaraftis (2017)

\begin{tabular}{|c|c|c|c|c|c|c|}
\hline \multirow[b]{2}{*}{ Route } & \multicolumn{3}{|c|}{ Market Share (\%) } & \multicolumn{3}{|c|}{ Scale parameter } \\
\hline & Maritime & $\begin{array}{l}\text { Maritime } \\
\text { competitor }\end{array}$ & Land & $\lambda$ & $\lambda_{1}$ & $\lambda_{M}$ \\
\hline Gothenburg - Ghent & $24-30$ & $21-29$ & $39-49$ & NA & 0.027 & 0.025 \\
\hline Esbjerg -Immingham & \multicolumn{2}{|c|}{$60-70$} & $30-40$ & 0.08 & \multirow{6}{*}{\multicolumn{2}{|c|}{ NA }} \\
\hline Rotterdam - Felixstowe & \multicolumn{2}{|c|}{$30-40$} & $60-70$ & 0.14 & & \\
\hline Copenhagen - Oslo & $20-25$ & NA & $75-80$ & 0.108 & & \\
\hline Klaipeda-Kiel & 51-61 & NA & $39-49$ & 0.019 & & \\
\hline Klaipeda - Karlshamn & $67-77$ & $23-33$ & NA & 0.08 & & \\
\hline Dover - Calais & $39-49$ & NA & $51-61$ & 0.015 & & \\
\hline
\end{tabular}

In the remainder of the chapter, with the examination of policy and operators measures, these average values of the scale parameters will be used for each case study. These values are in agreement with the dispersion parameters for freight transport of previous studies in the field (Lemper et al., 2009; Panagakos et al., 2014). Small values for $\lambda$ indicate a low shift potential for the same change in the disutility function modelled. Therefore, if the generalized cost of all services increases by the same amount as a consequence of the mandatory use of low-sulphur fuel, then the route with the lower dispersion parameter will lose a smaller market share to competing modes and is more resilient to change. Therefore, routes with larger scale parameters may be in need of more to be protected from potential service closures. The next section will analyze the effects of the proposed operators' measures.

\section{Operators' measures to cope with regulation}

Following discussions with relevant stakeholders, a set of measures that ship 
operators could readily deploy in response to potential modal shifts if fuel prices increase again was developed. The measures were selected and tailored in a way to be transferable to other types of shipping, and not limited to only Ro-Ro operations. The set consists of the following measures which will be briefly presented here:

- New sailing speed

- Alterations in sailing frequency of a service

- Fleet reconfiguration with exchanges of ships between services

- Investments in abatement technologies (scrubbers)

In the next sections each measure will be presented and its effects on the examined service and a summary of respective case studies will be shown. More detailed information can be found in Zis and Psaraftis (2018a, 2018b). For some of the case studies, sensitivity analyses on the effects of fuel price are conducted. Three such case studies are considered:

- Case 1 considers the actual prices as experienced in 2015,

- Case 2 is a pessimistic scenario with high fuel prices as in early 2014 ,

- Case 3 is a hypothetical scenario during which HFO with $1 \%$ sulphur is still allowed as before the regulation, with the 2015 prices.

\subsection{Effects of new sailing speeds in the service}

Even small reductions in sailing speed can bring significant fuel consumption economy in each journey. Therefore, for routes that are struggling with low traffic (reduced revenues) it may be an option to maintain a service financially viable. In contrast to other types of shipping, Ro-Ro services are faster and offer a high sailing frequency (multiple sailings per week, in certain short routes per day). This fact brings forth additional constraints on the viable ranges of sailing speeds. Due to the nature of the sector, most sailings are advertised (scheduled) to last an integer number of hours, or integer multiples of 30 minute periods. At the same time, typically departures and arrivals of most sailings are at sharp or half-past times. This facilitates the planning of cut-off times for the embarkation of goods and passengers. Finally, sailing speeds cannot be lowered at extreme levels in order to ensure a minimum turnaround time at each port for loading and unloading of vehicles.

For the examined services, we considered several different sailing speeds that would increase total sailing time by 30 minutes, 1 hour, 2 hours, up to 3 hours for the longer routes. For one route (Klaipeda - Kiel) we also considered increasing the sailing speed as this is what actually was observed in 2016. The effects of speed changes in the fuel consumption of vessels deployed in the applicable services are shown in Table 4.

Table 4: The effects of a new sailing speed on fuel consumption

\begin{tabular}{|l|c|c|c|c|}
\hline Route & $\begin{array}{c}\text { Hours at } \\
\text { berth }\end{array}$ & $\begin{array}{c}\text { Hours } \\
\text { sailing }\end{array}$ & $\begin{array}{c}\text { Weekly } \\
\text { fuel consumption } \\
\text { (tonnes) }\end{array}$ & $\begin{array}{c}\text { Change } \\
\text { (\%) }\end{array}$ \\
\hline
\end{tabular}




\begin{tabular}{|c|c|c|c|c|}
\hline \multirow{6}{*}{ Gothenburg - Ghent } & \multicolumn{4}{|c|}{ Baseline Sailing Speed 18.06 knots } \\
\hline & 38 & 130 & 286.9 & NA \\
\hline & \multicolumn{4}{|c|}{ Increase Trip by 1 hour, New Sailing Speed $\mathbf{1 7 . 3}$ knots } \\
\hline & 32 & 136 & 259.3 & -10.7 \\
\hline & \multicolumn{4}{|c|}{ Increase Trip by 2 hours, New Sailing Speed 16.5 knots } \\
\hline & 26 & 142 & 235.5 & -21.8 \\
\hline \multirow{6}{*}{$\begin{array}{c}\text { Esbjerg - } \\
\text { Immingham }\end{array}$} & \multicolumn{4}{|c|}{ Baseline Sailing Speed 18.11 knots } \\
\hline & 60 & 108 & 292.4 & NA \\
\hline & & ip by 0 . & ailing $S_{1}$ & \\
\hline & 57 & 111 & 274.1 & -6.3 \\
\hline & & rip by 1 & iling Spe & \\
\hline & 54 & 114 & 257.4 & -11.9 \\
\hline \multirow{6}{*}{ Copenhagen - Oslo } & \multicolumn{4}{|c|}{ Baseline Sailing Speed 15.5 knots } \\
\hline & 45.5 & 122.5 & 271.3 & NA \\
\hline & \multicolumn{4}{|c|}{ Increase Trip by 0.5 hours, New Sailing Speed 15.1 knots } \\
\hline & 42 & 126 & 257.9 & -4.9 \\
\hline & \multicolumn{4}{|c|}{ Increase Trip by 1 hour, New Sailing Speed 14.7 knots } \\
\hline & 38.5 & 129.5 & 245.9 & -9.4 \\
\hline \multirow{6}{*}{ Klaipeda - Kiel } & \multicolumn{4}{|c|}{ Baseline Sailing Speed 18.4 knots } \\
\hline & 26.5 & 129.5 & 321.1 & NA \\
\hline & \multicolumn{4}{|c|}{ Decrease Trip by 1.5 hour, New Sailing Speed 19.8 knots } \\
\hline & 35.5 & 120.5 & 373.8 & +16.4 \\
\hline & \multicolumn{4}{|c|}{ Increase Trip by 0.5 hours, New Sailing Speed 18 knots } \\
\hline & 23.5 & 132.5 & 305.9 & -4.7 \\
\hline
\end{tabular}

The average fuel consumption of the deployed vessels that were used in each route 
in the examined period is shown. The fuel consumption at the baseline sailing speeds was given from the ship operator, and estimations on the fuel consumption at other speeds were based on an in-house modelling tool that links speed with fuel consumption. Any changes in cargo volumes loaded are not considered in the fuel consumption. In reality, if due to the lower sailing speed the demand is reduced, this will result in a slightly lower fuel consumption due to the lower deadweight.

The next step of the analysis is to understand the effect of the lower sailing speed into modal choice, considering that no other change is introduced (e.g. the freight rates are remaining the same for all three Fuel Case scenarios as in the baseline). For speed reduction scenarios a minor loss of cargo is observed, which is due to the very low effect that the little extra time has on the generalized cost of transport. However, It must be stressed that if a very high depreciation rate was used and/or cargoes of very high values, then the loss due to slow steaming would be more severe. An overall observation is that the revenue remains relatively unchanged, whereas the cost of fuel is changing dramatically for lower speeds for all fuel case scenarios. For cruise routes, a side benefit of a higher sailing times is an increase in revenue from on-board spending (passenger facilities such as casinos, restaurants, bars). In terms of capacity utilization, fuel price plays a crucial role in its value whereas an increase in sailing time has a trivial effect. The effects on the capacity utilization are shown in Figure 6. 
Fuel Case 1

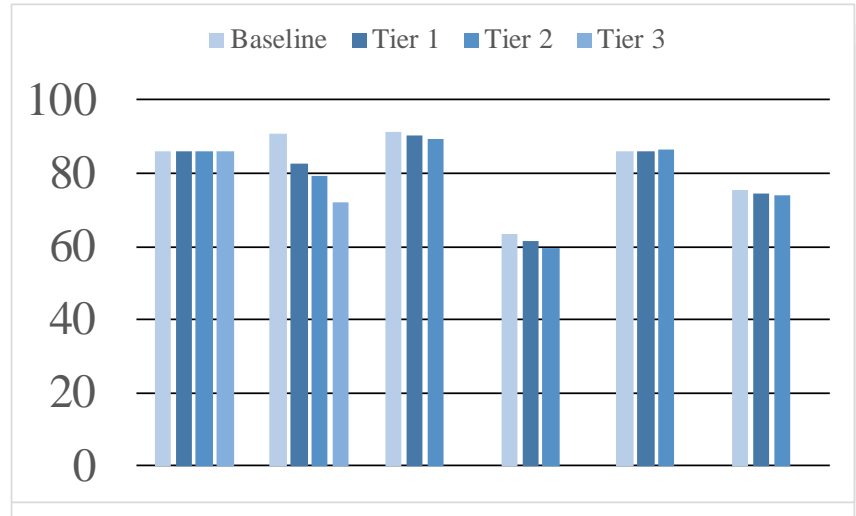

Fuel Case 2

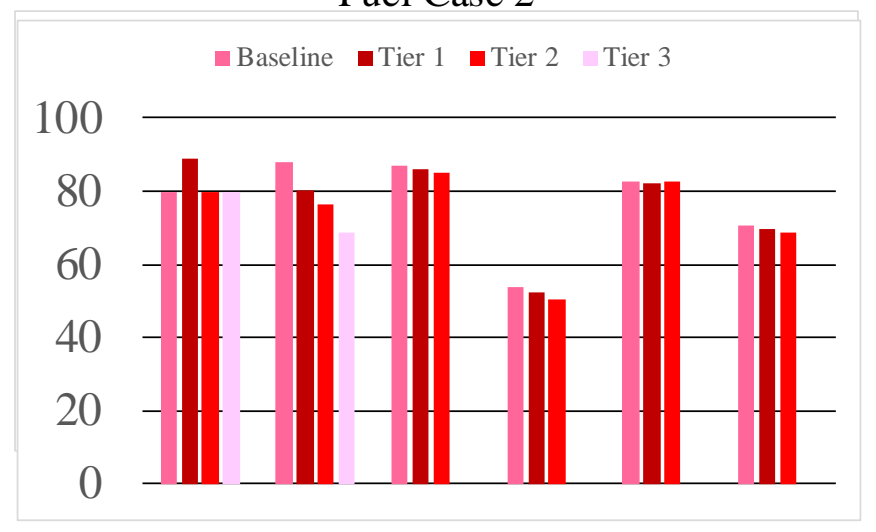

Fuel Case 3

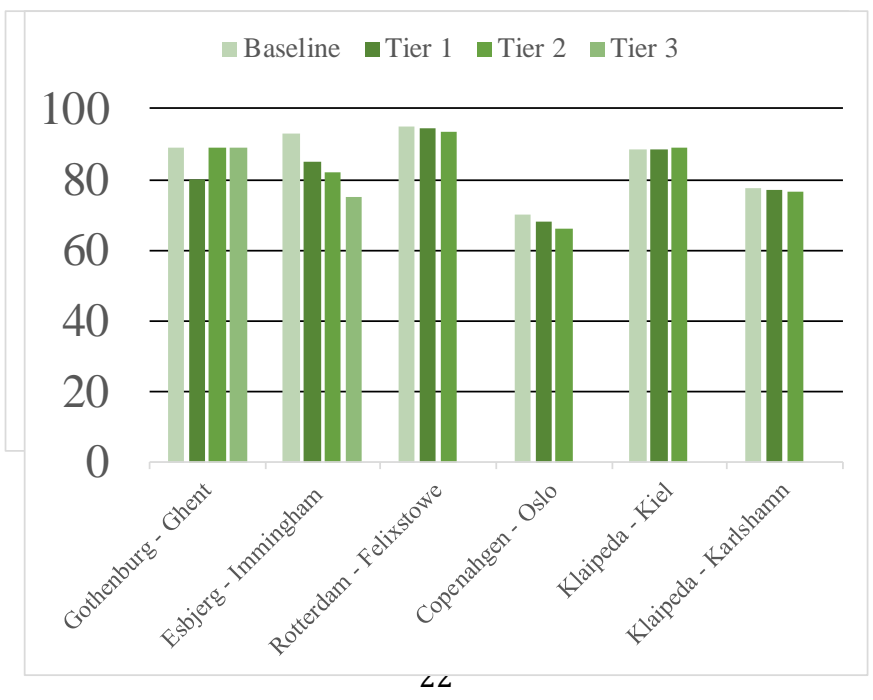


Figure 6: effects of speed changes on capacity utilization for different fuel price scenarios

In Figure 6, the first bar for each route shows the baseline capacity utilization without a change in sailing speed. The next bars correspond to different tiers of speed changes as in Table 4. It can be observed that with lower sailing speeds there is a reduction in the utilized capacity of the vessel (and thus revenues per trip), however the total fuel savings as seen in Table 4 far outweigh these revenue losses.

\subsection{Altering sailing frequency}

For certain services where profitability may be hindered due to loss of cargo volumes, an option may be to reduce the number of weekly sailings. Instead of shutting down a service completely, the sailing frequency may be adapted by either reducing the number of deployed vessels, or simply reducing the number of weekly sailings. While the market share will drop in such an event (as this is increasing the average travel times due to the increased inter-departure times), it is expected that it will increase the utilization rate and thus improve the profitability of the route.

This measure is examined for fuel prices in all fuel case scenarios, where in the Case 1 and 2 there is a small reduction in the sailing frequency, and a higher frequency for Case 3 (allowed use of HFO at 2015 price levels) due to increased demand. This measure is considered for three services where it is easily applicable, with no requirement for changing the number of deployed vessels. Table 5 provides a summary of results for a few scenarios.

Table 5: Effects of new sailing frequency

\begin{tabular}{|cccccc|}
\hline $\begin{array}{c}\text { Fuel } \\
\text { Case }\end{array}$ & $\begin{array}{c}\text { New } \\
\text { frequency }\end{array}$ & $\begin{array}{c}\text { Change in } \\
\text { transported units } \\
(\%)\end{array}$ & $\begin{array}{c}\text { Capacity } \\
\text { utilization }\end{array}$ & $\begin{array}{c}\Delta \text { Revenue } \\
(\boldsymbol{\epsilon})\end{array}$ & $\begin{array}{c}\Delta \text { Fuel } \\
\text { Cost } \\
(\boldsymbol{\epsilon})\end{array}$ \\
2 & 5 & Esbjerg - Immingham & (baseline 6 sailings per week) \\
3 & 7 & -6 & 96.6 & -112000 & -33500 \\
& & +3.1 & 82.02 & 40000 & 16600 \\
1 & 6 & Klaipeda - Kiel (baseline 7 sailings per week) & \\
2 & 6 & -3.1 & 97.36 & -32400 & -28170 \\
& & -2.8 & 96.19 & -25080 & -57090 \\
1 & 75 & Dover - Calais (baseline 99 sailings per week) & \\
2 & 75 & -5.37 & 94.63 & -56000 & -58900 \\
& & -5.39 & 88.25 & -74600 & -119300 \\
\hline
\end{tabular}

Table 5 shows that a lower sailing frequency for high fuel prices leads to significant increases in the utilization factor of the vessels, to a point where it would be 
undesirable. This is due to the assumption that the reduction would result in a small drop in transportation demand, as the service that would be cancelled could be for example a service that runs on a weekend. Comparing the revenue from transport units and the fuel consumption is not sufficient to deduce whether a new sailing frequency is preferable. The ship would also need to carefully consider the change in other operating costs (e.g. port fees, staff costs, depreciation).

\subsection{Fleet reconfiguration and vessel swaps}

This measure is essentially an adaptation of the sailing frequency option that the RoRo operator has. Instead of changing the sailing frequency, the Ro-Ro operator can consider a different fleet assignment between routes served by swapping vessels according to their key technical characteristics in terms of capacity, speed, and fuel consumption. There are certain constraints for the implementation of this measure. For example, vessels are assigned to existing services based on their type (pure cargo, or cargo + passenger vessels) and thus vessels can be swapped only between similar type services. Additional bureaucratic constraints may not allow the change of service for some of the vessels. For example, ships that were retrofitted with scrubber systems with subsidies from the European Commission were forced to run on the predetermined services.

The case study we examine in this section is or the swapping of vessels between two Ro-Ro services in the North Sea (Gothenburg -Ghent and Esbjerg - Immingham). This swap can be considered if there is a drop in transport demand in one route and a smaller vessel is assigned to it. The results of the analysis are shown in Table 6.

Table 6: Vessel swap between two North Sea services

\begin{tabular}{|c|c|c|c|c|}
\hline Route & \multicolumn{2}{|c|}{ Gothenburg - Ghent } & \multicolumn{2}{c|}{ Esbjerg - Immingham } \\
\hline $\begin{array}{c}\text { Fuel } \\
\text { Case }\end{array}$ & $\begin{array}{c}\text { Capacity utilization } \\
(\%)\end{array}$ & $\begin{array}{c}\Delta \text { FC } \\
(\boldsymbol{€})\end{array}$ & $\begin{array}{c}\text { Capacity utilization } \\
(\%)\end{array}$ & $\begin{array}{c}\Delta \text { FC } \\
(\boldsymbol{(})\end{array}$ \\
\hline $\mathbf{1}$ & 92.08 & -4660 & 94.32 & -11000 \\
$\mathbf{2}$ & 85.49 & -9500 & 91.45 & -22400 \\
$\mathbf{3}$ & 95.36 & -4500 & 96.59 & -10711 \\
\hline
\end{tabular}

For Gothenburg - Ghent the benefit is small for the low fuel price scenarios. The swap is considered with a smaller vessel currently sailing in a different service of the operator (Gothenburg - Immingham). For Esbjerg - Immingham the fuel savings can be important at high fuel prices as a more fuel-efficient vessel is moved from a less frequent service. The capacity utilization is not changing significantly due to the small diferece in maximum capacity of the vessels. We assume that a vessel swap would not affect the transportation demand for the service (the shipper is unaware of which ship is moving their cargo), considering that the vessel would sail at the same sailing speed and frequency. For Fuel Case 3, the fuel cost benefit is marginal and there $s$ the added risk of having vessels that are loaded extremely close to the maximum 
capacity which could backfire due to potential losses of revenues for not picking up cargoes.

\subsection{Scrubbers vs low sulphur fuel}

The decision of using low sulphur fuel has the advantage that it does not require a significant capital investment (for retrofits), at the expense of pricier fuel. Various cost benefit analyses have been conducted in recent years, and the common denominator in these studies is that the fuel price differential is critical on whether the retrofit is a good option. More detailed information can be found in the literature (Jiang et al., 2014; Zis et al; 2016). The ship operator of the examined network already has a significant number of their vessels retrofitted with scrubber systems. In this case study, a hypothetical conversion of the most fuel consuming vessel (that currently uses MGO) is considered. We assume that the conversion would be performed on the first of January 2015. We use a typical retrofit cost of $€ 250$ per $\mathrm{kW}$ of installed main engine power, and thus the capital cost of investment lies in the region of approximately 4.8 $M €$. The total weekly fuel consumption for the vessel reaches 303 tons. Following an installation of scrubbers, the additional fuel consumption is assumed to be $3 \%$ to cover the scrubber's energy requirements (estimate on the high end of the range). The operating cost savings depends on the fuel price differential of HFO and MGO. At the highest fuel prices observed in the two years between 2014 and 2015, the investment in scrubber systems would seem as very promising with a payback period that was less than two years. In contrast, taking into account the lowest fuel prices observed in the end of 2015 (and very low fuel price differential), the payback period would increase to 4.3 years e.g. 2020. By 2020, the global sulphur cap will be enforced and potentially new technologies will be available that would constitute investing in scrubbers in 2016 less appealing. Considering these simplistic calculations, the age of the vessel should also be taken into account as if a vessel has less than 5 years of remaining service, investing in scrubbers may not make sense.

Other measures that the operator could use to cope with such regulations would be the potential use of Liquefied Natural Gas (LNG) as fuel (particularly for the post-2020 era of the global sulphur cap). The ship operator could also consider changing their Bunker Adjustment Factor (BAF) in order to better capture the impacts of the premium they have to pay on low sulphur fuel, in such a way that the shippers are not tempted to change modes (or shipping company). Finally, in the section each of the measures in the case studies were presented on a one by one basis. However, a ship operator could do more than one at the same time. In the RoRoSECA project website ${ }^{2}$, a free software tool has been developed that allows the examination of more than one operational measures on the shippers choice, ship operators' profitability as well as the system's environmental performance (all available transport modes at each service scenario).

\section{Policy measures}

\footnotetext{
${ }^{2}$ www.roroseca.transport.dtu.dk
} 
The previous operators' measures may prove critical in the survival of certain services in the event of a re-emergence of high fuel prices in the near future. Even in the event that fuel prices remain at low levels, the operators may also need to fine-tune their services in order to maximize the financial performance of a route. However, during extreme fuel prices the operators' measures may not be sufficient to revert the negative impacts of the SECA limits. This section of the book chapter presents potential policy measures that could be used to offset the potential modal backshifts that could result from an increase in fuel prices. More detailed information on the examined case studies is available in the RoRoSECA website in the deliverable on Task 3.2 entitled "Measures from policy makers "of the RoRoSECA project (Zis et al., 2017). This section draws heavily from that report.

\subsection{Internalization of external costs}

This measure considers the full or partial internalization of external costs associated with the transportation of the examined routes and the various modes used. Transport generates negative externalities that involve a cost to society and economy. Internalising these would encourage the use of safer, more silent and environmentally friendly vehicles.

In the examined case studies, the external costs are added to the transport cost element in the generalized cost formulation used in the modal shift models. Various different specifications can be considered for the internalization process. Figure 7 illustrates the process of internalization of external costs, as a measure to combat the negative effects of the low sulphur fuel requirements.

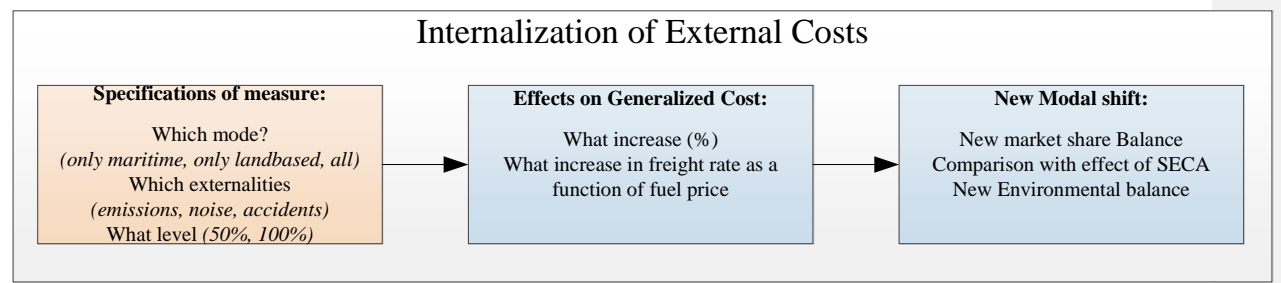

Figure 7: The internalization of external costs as a potential policy measure

A potential internalization of external costs may include all of these externalities, or merely a sub-set of them, and the effects of a partial (here we examine 50\%) or full internalization will be considered. The second step considers the actual monetary effect of such a measure to the generalized cost of transportation for one unit of transport, in the different routes and for the different project specifications. The third and final step, would be the use of the modal shift model (see section 2 of this chapter) to estimate the new market shares of the competing transportation modes. The effects of this measure are then to be compared with the effects of the $0.10 \%$ sulphur limit on the short sea shipping sector, and the impacts on emissions generation.

A critical decision in such measures is who would actually be responsible for the payment of the additional cost. In this section the assumption is that the shipper has to pay an additional contribution that is calculated as a function of the allocated emissions for the transportation of the cargo. It can be argued that in such a measure, 
the ship/freight operator would have to pay according to the emissions and transport work produced. The external costs used in this study are adapted from the DTU study on policy measures (Zis et al., 2017), more information on the derivation or these values is available in the deliverable report. Two main sources were used for these values, the study of COWI/DTU (2015) and the 2014 Handbook for the European Commission (Ricardo-AEA, 2014) on external costs.

These costs will be examined, but it can be anticipated that if the operator is paying for the externalities, these additional costs would in some manner be passed on to the shipper. There can also be an expected volatility in the values of these costs, and a significant increase in the transportation costs for each mode. Consequently, it can be anticipated that such a measure could lead in an overall reduction in transport demand from an economics perspective.

For services that also carry passengers the way the emissions would be allocated between cargo and passengers is not standard, and there can be great variability. For the sake of comparison across the routes, the next section assumes that all emissions are always attributed to the cargo even though that would not be realistic in an internalization scenario. For the maritime modes, the emissions at the port are considered for $\mathrm{CO}_{2}, \mathrm{SO}_{x}, \mathrm{NO}_{x}$ and $\mathrm{PM}_{2.5}$ emissions, while at the sailing phases only the $\mathrm{CO}_{2}$ emissions are internalized. The values used in this chapter per $\mathrm{kg}$ of pollutant are the following (Zis et al., 2017):

- For $\mathrm{CO}_{2} € 0.11 / \mathrm{kg}$ (at sea and at port)

- For $\mathrm{SO}_{x} € 12.96 / \mathrm{kg}$ (at port)

- For $\mathrm{NO}_{x} € 13.47 / \mathrm{kg}$ (at port)

- For $\mathrm{PM}_{2.5} € 50.15 / \mathrm{kg}$ (at port)

It should be noted that this is only one set of possible values for the external cost per pollutant species, and there are other variations (low or higher estimates) per pollutant, and there are also variations depending on the region where the pollutants are emitted. More analytical information is shown in the project's report (Zis et al., 2017). For Gothenburg - Ghent more analytical results are presented in Figure 8 using different combinations of scenarios (full internalization of $\mathrm{CO}_{2}$ only, or of all emissions, in combination with the different levels of the external cost values - low, medium, high). 
External costs of emissions in Gothenburg - Ghent $(€ / \mathrm{lm})$

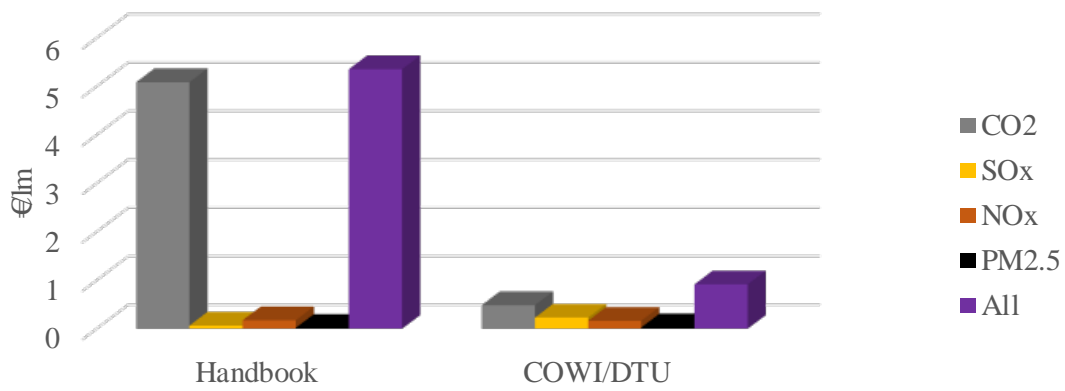

Figure 8: Breakdown of external costs of transport for Gothenburg - Ghent. Source: Zis et al. (2017)

Figure 8 shows that the main difference for both methodologies is due to the cost of carbon emissions. If all pollutants external costs are internalized, there is a significant increase in the total external cost per lane meter at this route. Figure 9 summarizes the cost of internalization per unit transport as compared to the freight rate of each route for the two fuel case scenarios, assuming full emissions allocation to the cargoes.
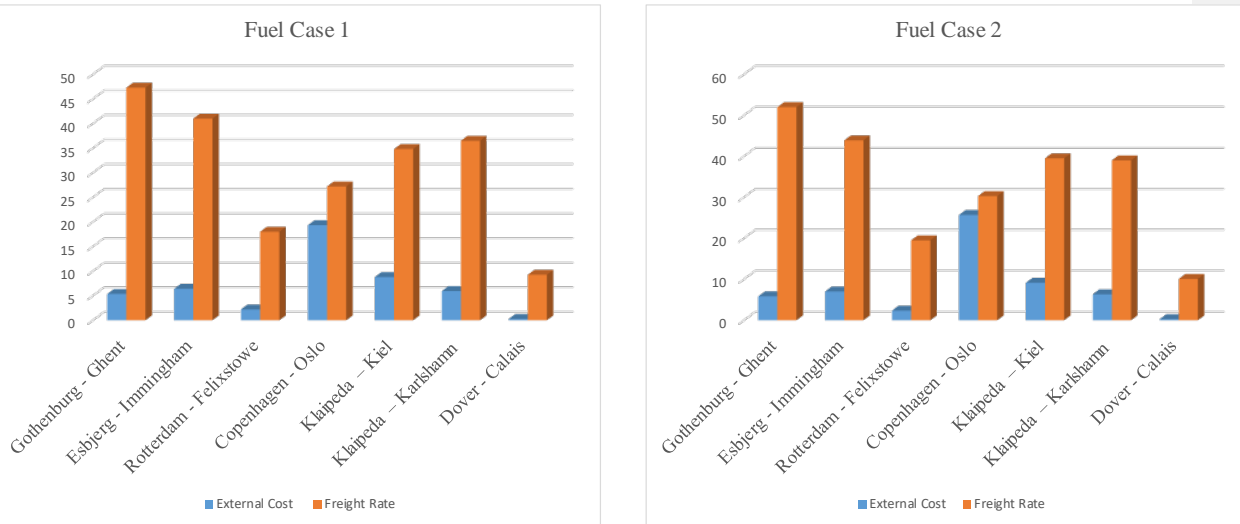

Figure 9: Cost of internalization of emissions for each route. Source: Zis et al. (2017)

It is evident that for the cargo routes the external costs are between 10 and $16 \%$ of the freight rate for both fuel case scenarios.

\subsection{Easing the port dues of a ship operator}

This measure is considering the option of subsidising part of the port dues that the affected ship operators have to pay during their vessel calls. The rationale behind this 
measure is that since there are lower emissions as a consequence of the regulation (during the approach/departure phases) it may be reasonable to reduce the port fees by a certain extent. Retrieving information on the actual port fees for each vessel call is possible through the websites of the respective port authorities. For example, the port of Esbjerg charges 7.95 DKK (approximately €1.07) per GT per month for a visiting vessel, that in the case of the two vessels accounts for approximately 0.85 million $€$ a year. Esbjerg ${ }^{3}$ is then providing a $90 \%$ refund of this cost in the next year if the vessel is a Ro-Ro ship. In contrast, the port of Immingham ${ }^{4}$ has a tariff of $£ 3.98$ per NT just for the port and the examined vessels have a net tonnage of approximately 10000. In addition, different ports have additional costs for mooring, waste charges, dock rents, fairway dues in certain countries etc. While most of these costs are available online, the actual costs paid by frequent callers (as in the case of Ro-Ro services) are not public. For this reason, the actual port dues that the collaborating ship operator was paying was used in this analysis. These are shown in Table 7.

Table 7: Port fees vs fuel costs as \% of operating costs

\begin{tabular}{|l|c|c|}
\hline Route & $\begin{array}{c}\text { Port cost as \% of operating } \\
\text { costs }\end{array}$ & $\begin{array}{c}\text { Fuel costs as \% of operating } \\
\text { costs }\end{array}$ \\
\hline Gothenburg - Ghent & 4.6 & 30 \\
\hline $\begin{array}{l}\text { Esbjerg } \\
\text { Immingham }-\end{array}$ & 4.2 & 30 \\
\hline $\begin{array}{l}\text { Rotterdam } \\
\text { Felixstowe }\end{array}$ & 4.5 & 21 \\
\hline Copenhagen - Oslo & 4.7 & NA \\
\hline Klaipeda - Kiel & 6.8 & 21 \\
\hline $\begin{array}{l}\text { Klaipeda } \\
\text { Karlshamn }\end{array}$ & 4.9 & 23 \\
\hline Dover - Calais & 14.7 & 39 \\
\hline
\end{tabular}

Table 7 shows that the port costs in the year are a very small component of the overall operating cost for each service, with the exception of Dover Calais with a very high number of port calls a year. If a subsidy is provided to the ship operators towards their port dues, this could amount (for a full refund) to between 1.2 and 8 million $€$ per year, which is similar for most routes to the cost of simply covering the BAF surcharges as seen in section 4.4 .

\section{3 http://portesbjerg.dk \\ 4 http://www.humber.com}




\subsection{ECO-bonus system}

The first ECO-bonus system was authorized by the European Commission as a temporary state aid scheme in Italy for freight operators moving from road to sea. The main objective of ECO-bonus was to establish a mechanism to promote short sea shipping (Tsamboulas et al., 2015). The first implementation of the scheme, considered the provisions of $20 \%$ towards the seaway tariffs of services (up to $30 \%$ for new services to be introduced after the system), while setting certain minimum limits (in terms of annual trips by the benefited operator). Due to limited resources and the ensuing recession, this scheme was operational only for a little bit over two years. However there are now new efforts attempting to replicate similar schemes.

In Norway, shipping lines that seek to establish new cargo services in the country can apply for grants from the Norwegian Coastal Administration. For this scehme, the aid goes directly to the ship operator and can be either the environmental benefit of the modal shift, the $30 \%$ of the operating costs of the service, or a $10 \%$ of the transhipment equipment costs. In Italy, two additional state aid schemes were approved from the European Commission targeting modal shifts towards rail and sea. The maritime scheme is called Marebonus, and will have a budget of $€ 138$ million. These subsidies will be used for the introduction of new services, or upgrades to existing sea routes (Danesi and Longhi, 2016). Finally, work on an ECO-bonus like system is currently conducted by the MED-Atlantic ecobonus project (co-funded by the EC) that seeks to increase the use of MoS in the Western Mediterranean and Atlantic markets.

In the context of this chapter annual costs for such schemes are estimated the seven routes of the case study, and the arising modal shifts the lower generalized cost of maritime transport options are estimated. We assume the provision of a $20 \%$ subsidy on the freight rate paid in each service for all customers (new and old) during 2015, and the impact this would have on the market shares of the examined service (additional \%share captured).

Table 8: Cost and impacts on market share of a $20 \%$ subsidy to shippers. Source: Zis et al. (2017)

\begin{tabular}{|l|l|l|}
\hline Route & Fuel Case 1 & Fuel Case 2 \\
\hline \multicolumn{3}{|c|}{ Gothenburg - Ghent } \\
\hline Modal shift & $+5.93 \%$ & $+6.18 \%$ \\
\hline Total Policy Cost $(€)$ & $21 \mathrm{M}$ & $23 \mathrm{M}$ \\
\hline \multicolumn{3}{|c|}{ Esbjerg - Immingham } \\
\hline Modal shift & $+13.6 \%$ & $+16 \%$ \\
\hline Total Policy Cost $(€)$ & $14.6 \mathrm{M}$ & $14.9 \mathrm{M}$ \\
\hline \multicolumn{3}{|c|}{ Rotterdam - Felixstowe } \\
\hline
\end{tabular}




\begin{tabular}{|c|c|c|}
\hline Modal shift & $+10.92 \%$ & $+10.95 \%$ \\
\hline Total Policy Cost $(€)$ & $17.6 \mathrm{M}$ & $19.5 \mathrm{M}$ \\
\hline \multicolumn{3}{|c|}{ Copenhagen - Oslo } \\
\hline Modal shift & +10.63 & +9.97 \\
\hline Total Policy Cost $(€)$ & $4.5 \mathrm{M}$ & $5.4 \mathrm{M}$ \\
\hline \multicolumn{3}{|c|}{ Klaipeda - Kiel } \\
\hline Modal shift & $+3.2 \%$ & $+3.67 \%$ \\
\hline Total Policy Cost $(€)$ & $9.3 \mathrm{M}$ & $10.7 \mathrm{M}$ \\
\hline \multicolumn{3}{|c|}{ Klaipeda - Karlshamn } \\
\hline Modal shift & +10.55 & $+12.4 \%$ \\
\hline Total Policy Cost $(€)$ & $11.1 \mathrm{M}$ & $12.4 \mathrm{M}$ \\
\hline \multicolumn{3}{|c|}{ Dover - Calais } \\
\hline Modal shift & $+3.9 \%$ & $+4.24 \%$ \\
\hline Total Policy Cost $(€)$ & $14.2 \mathrm{M}$ & $15.7 \mathrm{M}$ \\
\hline
\end{tabular}

The results show that such schemes could be very successful in attracting additional customers using the Ro-Ro links, however the cost would be very high if applied to all users. In case a pilot implementation was considered, whereby the refund would be provided only to new users of the link, the cost would be proportionally lower. It is clear that such a policy would have an objective of increasing the users of maritime services, and not simply to reverse the negative effects of the low-sulphur regulation, as the monetary incentive exceeds the actual surcharge imposed on shippers because of low-sulphur fuel use. A subsidy of a different level could also be considered as a potential measure and could be the subject of interesting academic research.

\subsection{Subsidies for the bunker adjustment factor (BAF)}

The exact value of BAF depends on various service characteristics, including length, frequency, sailing speed, and ship type. In this work, the BAF policy of the ship operator providing most of the data is used. The annual costs for the policy body are shown in Table 9.

Table 9: Impacts of subsidizing the BAF surcharges Source: Zis et al. (2017)

\begin{tabular}{|l|l|l|l|c|} 
Route & Gothenburg & Esbjerg & Klaipeda & Dover \\
\hline
\end{tabular}




\begin{tabular}{|l|c|c|c|c|c|c|c|c|}
\hline & \multicolumn{2}{|c|}{ Ghent } & \multicolumn{2}{|c|}{ Immingham } & \multicolumn{2}{c|}{ Kiel } & \multicolumn{2}{c|}{ Calais } \\
\hline Fuel Case & 1 & 2 & 1 & 2 & 1 & 2 & 1 & 2 \\
\hline BAF $(€ / I m)$ & 1.37 & 5.13 & 1.19 & 4.3 & 1.76 & 6.34 & 0.33 & 1.2 \\
\hline Cost $(\mathrm{M} €)$ & 2.5 & 10.1 & 1.96 & 7.82 & 2.27 & 8.48 & 2.35 & 9.0 \\
\hline $\begin{array}{l}\text { Change in } \\
\text { capacity utilization }\end{array}$ & $+2.5 \%$ & \multicolumn{2}{|c|}{$+3.5 \%$} & $+1.43 \%$ & $+1.6 \%$ \\
\hline
\end{tabular}

If the fuel prices were as high as in early 2014 , then the policy would cost approximately 4 times more for each route. The lower costs in Case 1 essentially represent the effects of the SECA limit on the shippers using this service. If the BAF was paid back to the shippers, then services would increase their market share, and sail at increased utilization rates. .However, a uniform policy to refund the shippers using the maritime mode shows that it will be very costly, considering that the annual policy costs shown in Table 9 are for just one of the numerous affected services.

\subsection{Additional Road tax to reverse modal shifts}

This measure considers the identification of the necessary increase in the land-based freight rates that a shipper must pay, in order to negate the modal shift loss that is triggered by the low sulphur fuel requirement. It is evident that this is a very case specific measure, as the necessary increase per land-based transport work (in Im-NM units) will depend on the relative weight of the maritime costs in the generalized cost of the shipper. An explanatory analysis is conducted where the objective is to identify what percentage increase in the total monetary cost of land-based transport options will result in absorbing the modal backshift attributed to the low sulphur fuel requirement. The necessary percentage increases are summarized in Table 10, for the two fuel price scenarios. For the Dover - Calais service, the percentage increase refers to the Eurotunnel cost. For Klaipeda - Karlshamn this measure was not considered due to the lack of competition with land-based options.

Table 8: Necessary tax (\% of freight rate) to reverse modal splits caused by $0.10 \%$ sulphur limit. Source: Zis et al. (2017)

\begin{tabular}{|l|l|l|}
\hline Route & Fuel Case 1 & Fuel Case 2 \\
\hline Gothenburg - Ghent & 3.83 & 14.48 \\
\hline Esbjerg - Immingham & 2.48 & 8.95 \\
\hline Rotterdam - Felixstowe & 3.3 & 11.88 \\
\hline Copenhagen - Oslo & 7.15 & 25.8 \\
\hline
\end{tabular}




\begin{tabular}{|l|l|l|}
\hline Klaipeda - Kiel & 3.52 & 12.68 \\
\hline Klaipeda - Karlshamn & \multicolumn{2}{|c|}{ NA } \\
\hline Dover - Calais & 2.12 & 7.74 \\
\hline
\end{tabular}

Table 10 shows that the examined Ro-Ro services would be at considerable risk for high fuel prices. The necessary increase in the land-based option to offset the effects of the higher BAF is increasing significantly in with higher fuel prices. The wide variance of the necessary land-based tax is evidence of the sensitivity of the total road lengths in the shippers' decision making process. Therefore, suggesting a flat levy at $10 \%$ (e.g. in the form of an additional tax on petrol) would lead to net modal shifts towards maritime services for most routes).

\subsection{Subsidies for abatement technologies}

As presented in section 3.4, one of the operators' measures that was examined was the investments in abatement technologies such as scrubbers or LNG engines. From the operator's perspective, the main question in such investments is the net present value and the length of the payback period. Companies that have already invested in such technologies can be considered as an early adapter to the technology in terms of size of investment (number of vessels). The European Commission, under the Motorways of the Sea (MoS) programme provided subsidies of $20 \%$ for the retrofitting of vessels, with indicative costs of $1.5 \mathrm{M} €$ per vessel. The assumption of this measure is that a policy body would cover $20 \%$ of the required investment costs for each retrofit. This analysis is only conducted to compare the total costs with the previously examined measures. The actual costs of a retrofit were taken based on published estimates as a function of total installed power $(250 € / \mathrm{kW})$. The costs are summarized in Table 11.

Table 9: Retrofit subsidy requirements Source: Zis et al. (2017)

\begin{tabular}{|l|c|c|}
\hline \multicolumn{1}{|c|}{ Route } & $\begin{array}{c}\text { Number } \\
\text { of deployed Vessels }\end{array}$ & $\begin{array}{c}\text { Retrofit } \\
\text { subsidy (M€) }\end{array}$ \\
\hline Gothenburg - Ghent & 3 & 6 \\
\hline Esbjerg - Immingham & 2 & 3.9 \\
\hline Rotterdam - Felixstowe & 3 & 6.6 \\
\hline Copenhagen - Oslo & 2 & 4.7 \\
\hline Klaipeda - Kiel & 2 & 4.3 \\
\hline Klaipeda - Karlshamn & 2 & \\
\hline
\end{tabular}




\begin{tabular}{|l|c|c|}
\hline Dover - Calais & 2 & 4.4 \\
\hline
\end{tabular}

It can be seen that such a policy would require significant funds for the installation of scrubbers on all the available vessels. However, these costs are one-off (unlike other policies that could be annual) and in theory could be combined with a requirement that the benefitted ship operators would reduce the BAF surcharge since they could still use HFO.

\section{Conclusions, ongoing and future work}

The previous sections presented the first implications of the low-sulphur regulation on ship operators, shippers, and their effects on the environmental balance. The focus has been the lower limit within SECAs since 2015. Despite initial concerns that the limit would have devastating effects on the economy of the market, the unexpectedly low fuel prices actually boosted the sector. In terms of emissions reduction the limit was a considerable success. This is evident in Figure 10 where the relative emissions per transported work of cargo (assuming all emissions are allocated to cargo and the passengers are not included in the calculation) is shown in 2014 and 2015.
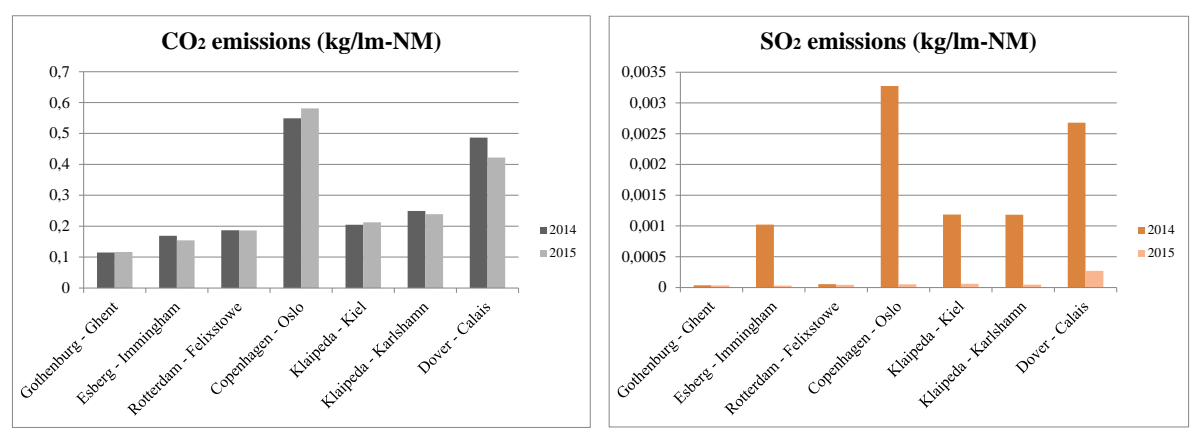

Figure 10: Emissions intensity (kg/lm-NM) for $\mathrm{CO} 2$ and $\mathrm{SO} 2$ in the examined routes. Source: Zis and Psaraftis (2017)

While absolute carbon emissions were increased (more trips performed in 2015, and in some routes higher sailing speeds were used), the emissions intensity was improved. For sulphur emissions the reduction had been proportional to the lowered limit. However, if fuel prices increase again the emissions intensity may be increased. A thorough modelling framework has been constructed that allows the estimation of potential modal shifts of regulations such as the SECA limits, but could easily also examine impacts of other regulations (e.g. if limits on other types of pollutants are placed, any bunker levies, speed limits, or other MBM). Free software tools are available in the RoRoSECA project website that allow such analyses. A set of policy and operational measures were proposed that can be used to mitigate and reverse any negative effects of the regulation.

\subsection{Early adapters}

Some ship operators started investing in scrubber systems before the new limit, at a time of high fuel prices and with concerns that low sulphur fuel would be extremely 
expensive after 2015 due to the new demand. These early adapters took a major risk, as they committed significant capital to prepare for the regulation. The market for abatement technologies is increasing and the technology is improving which will make it more affordable in the near future ahead of the global sulphur cap. In the European Union, early adapters were rewarded with subsidies towards the investment costs of the scrubber solution. However, certain constraints were put in place. For example, ship operators that benefited from such subsidies would need to sail on specified routes that limits their flexibility. Another risk is that new regulations may constitute the existing scrubber systems as non-compliant, or simply require additional significant capital costs for the abatement of different pollutant species (for example Black Carbon). As a result, the option of not investing in 'one-off' solutions, but instead relying on pricier low-sulphur fuel, may offer higher flexibility on ship operators. However technological progress can only occur if some operators start investing in such solutions, so that knowledge is generated and issues are resolved in the next versions of such solutions. It is therefore important to develop policies that help technological progress, and also incentivize early adapters (ship operators).

\subsection{The global sulphur cap}

It can be argued that the SSS operators caught a lucky break with the low fuel prices since 2014 until 2018, and the expected storm never hit them. Similar regulations that are targeting environmental impacts of the sector, can be expected to affect key stakeholders in various ways. Indeed, the introduction of the Energy Efficiency Design Index (EEDI), the potential expansion of emission trading schemes (ETS) to cover emissions from the shipping sector, as well as the introduction of the global $0.5 \%$ sulphur cap, can all have the potential of being game changers. Particularly for scrubber systems, the coming of the global sulphur cap in 2020 is expected to raise the demand for such technologies, especially if the low-sulphur fuel availability is not enough to cover the necessary demand. However, a turn of the industry to scrubber technologies may in turn potentially increase the demand for HFO in contrast to what is anticipated, and thus raise its price and reduce the fuel price differential with $0.5 \%$ fuel (and thus the benefit of investing in scrubber systems). Therefore, the impacts of environmental policies are much more complicated and difficult to predict, as it has been shown with the lowering of sulphur limits within SECAs. It is therefore vital to propose policies that mitigate the possible negative impacts of such regulation which will (post 2020) affect more severely the whole shipping sector and not just the relatively niche SSS. Therefore there are important research questions to be examined ahead of the global sulphur cap:

- How will the different levels of fuel availability affect the decision of ship operators to invest in scrubber systems?

- Will the global sulphur cap result in lower sailing speeds in the different shipping markets?

- How are the freight rates going to be affected, and will that lead into new modal shifts to other modes and new links like the One Belt One Road initiative?

- How can a level playing field be ensured?

5.3 The challenge of enforcing sulphur regulations

With regards to the last research question in section 5.2 , a new project at DTU is 
underway that seeks to answer this specific item. The new project is entitled SulphurGATE (Enforcement of Sulphur regulations; a Game Theoretic Approach). The purpose of the project is to develop a game theoretic modelling framework that improves the effectiveness of sulphur regulations enforcement. The existing legislative framework poses several challenges, stemming (mainly) from a highly nonhomogeneous and spatially differentiated system, with cases where the penalty fines are as low as the benefit that the violator enjoyed from not complying. This project will examine the status quo of enforcement in different countries, where the regulation applies, and use a game theoretic approach for a uniform violation fine system. Such a system can help ship owners that currently have invested heavily in an abatement of options to comply with the sulphur regulations, by maintaining a level playing field amongst ship operators, while at the same time improve compliance rates and maximize societal environmental benefits. In anticipation of the global sulphur cap in 2020 , it is expected that findings from the new project could form the basis for a new penalty system worldwide. 


\section{ACKNOWLEDGMENTS}

Much of the work presented in this chapter is in the context of the project: "Mitigating and reversing the side-effects of environmental legislation on Ro-Ro shipping in Northern Europe" (also known as the RoRoSECA project) funded by the Danish Maritime Fund and the Orients Fund. We are grateful to Poul Woodall of DFDS whom we worked with in this project, for the provision of data and valuable input and discussions in producing this work.

\section{REFERENCES}

Ben-akiva, M., Bradley, M., Morikawa, T., Benjamin, J., Novak, T., Oppewal, H., and Rao, V. (1994). Combining revealed and stated preferences data. Marketing Letters, 5(4), 335-349.

Buhaug, Ø., Corbett, J., Endresen, O., Eyring, V., Faber, J., Hanayama, S., Lee, D., Lindstad, H., Mjelde, A., Palsson, C., Wanquing, W., Winebrake J. and Yoshida, K. (2009) Second IMO Greenhouse Gas Study. International Maritime Organization, London

COWI/DTU (2016). Transport Economic Unit Prices for use in socio-economic analyses - Version 1.6 (in Danish). (Accessed 14/2/2017).

Crowley, T. J. "Causes of climate change over the past 1000 years." Science 289.5477 (2000): 270-277.

Cullinane, K. and Bergqvist, R. (2014). Emission control areas and their impact on maritime transport. Transportation Research Part D: Transport and Environment, 28, $1-5$.

Cullinane, K., and Cullinane, S. (2013). Atmospheric emissions from shipping: The need for regulation and approaches to compliance. Transport Reviews, 33(4), 377401.

Danesi, A., \& Longhi, M. (2016). OPENING THE SOUTHERN DOOR OF THE ITALIAN INLAND WATERWAY TRANSPORT NETWORK. Transport \& Logistics, 16(41).

DMA (2012). A feasibility study for an LNG filling station infrastructure and test of recommendations. North European LNG Infrastructure Project. Available at: https://www.dma.dk/Vaekst/EU/Documents/LNG Full report 20120524 optimerad.p df Accessed May 2017

EMSA (2010) European Maritime Safety. The $0.1 \%$ sulphur in fuel requirement as from 1 January 2015 in SECAs-An assessment of available impact studies and alternative means of compliance 
European Commission (2008). Directive 2008/50/EC of the European Parliament and of the Council of 21 May 2008 on ambient air quality and cleaner air for Europe. Official Journal of the European Union.

Eyring V., Köhler H.W., van Aardenne J. and Lauer A. (2005) Emissions from international shipping: 1. The last 50 years. Journal of Geophysical Research: Atmospheres 110(D17)

Henriksson, T. (2007). SOx scrubbing of marine exhaust gases. Wärtsilä Technical Journal, 2007(2), 55-58.

IMO (2014). Third IMO GHG Study 2014. International Maritime Organization (IMO), London. Available at: http://www.iadc.org/wp-content/uploads/2014/02/MEPC-67-6INF3-2014-Final-Report-complete.pdf [accessed June 2015]

Jiang, L., Kronbak, J., \& Christensen, L. P., (2014). The costs and benefits of sulphur reduction measures: Sulphur scrubbers versus marine gas oil. Transportation Research Part D: Transport and Environment, 28, 19-27

Lemper, B., Hader, A., Hübscher, A., Maatsch, S., \& Tasto, M. (2009). Reducing the sulphur conten of shipping fuels further to $0.1 \%$ in the North Sea and Baltic Sea in 2015: Consequences for shipping in this shipping area. Final report. Institut für Seeverkehrswirtschaft und Logistik. Bremen.

Odgaard, T., Frank, C., Henriques, M., and Bøge, M. (2013). The impact on short sea shipping and the risk of modal shift from the establishment of a NOx emission control area in the North Sea. Available at: http://eng.mst.dk/media/mst/9149808/theimpactonshortseashippingandtheriskofmod alshiftfromtheestablishmentofanecafina. (accessed April 2016)

Ortúzar, J. d. D. and Willumsen, L. G. (2011). Modelling Transport, Fourth Edition, John Wiley \& Sons

Panagakos, G. P., Stamatopoulou, E. V., \& Psaraftis, H. N. (2014). The possible designation of the Mediterranean Sea as a SECA: A case study. Transportation Research Part D: Transport and Environment, 28, 74-90.

Pickering, K. T., and Owen, L. A. (1997). An introduction to global environmental issues (Vol. 2). Psychology Press.

Ricardo-AEA (2014). Update of the Handbook on External Costs of Transport. Report for the European Commission DG MOVE, London.

Tsamboulas, D., Chiappetta, A., Moraiti, P., \& Karousos, I. (2015). Could Subsidies for Maritime Freight Transportation Achieve Social and Environmental Benefits? The Case of Ecobonus. Transportation Research Record: Journal of the Transportation Research Board, (2479), 78-85.

Ward, P. L. (2009). Sulfur dioxide initiates global climate change in four ways. Thin solid films, 517(11), 3188-3203. 
Zis, T. (2015). The Implications and trade-offs of near-port ship emissions reduction policies.

Zis, T., Angeloudis, P., Bell, M. G., \& Psaraftis, H. N. (2016). Payback Period for Emissions Abatement Alternatives: Role of Regulation and Fuel Prices.

Transportation Research Record: Journal of the Transportation Research Board, (2549), 37-44.

Zis, T., \& Psaraftis, H. N. (2018a). Operational measures to mitigate and reverse the potential modal shifts due to environmental legislation. Maritime Policy \& Management, 1-16.

Zis, T., \& Psaraftis, H. N. (2018b). Key performance indicators to assess and reverse the negative impacts of SECAs policies for Ro-Ro shipping. FME Transactions, 46(3), 347-354.

Zis, T., \& Psaraftis, H. N. (2017). The implications of the new sulphur limits on the European Ro-Ro sector. Transportation Research Part D: Transport and Environment, 52, 185-201.

Zis, T., Panagakos, G., Kronbak, J., \& Psaraftis, H. N. (2017). Report on the outcome of Task 3.2 "Measures from policy makers". Available at:

http://www.roroseca.transport.dtu.dk/dissemination 